\title{
Managing Travel Fatigue and Jet Lag in Athletes: A Review and Consensus Statement
}

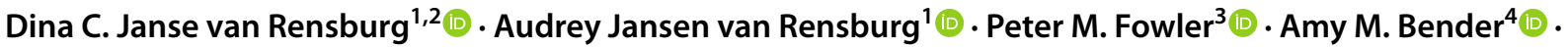

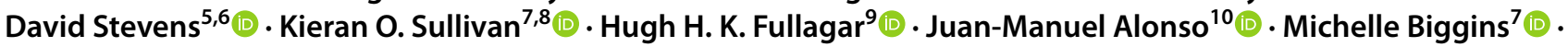 \\ Amanda Claassen-Smithers ${ }^{11}(\mathbb{0}) \cdot$ Rob Collins $^{12,13} \cdot$ Michiko Dohi $^{14} \cdot$ Matthew W. Driller $^{15}$ (1) $\cdot$ Ian C. Dunican ${ }^{16}$ (1) \\ Luke Gupta $^{17}$. Shona L. Halson ${ }^{18}$ (1) Michele Lastella ${ }^{19}$ (1) Kathleen H. Miles ${ }^{20}$ - Mathieu Nedelec ${ }^{21}$ (1)

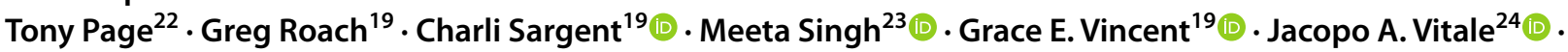 \\ Tanita Botha ${ }^{25}$ (1)
}

Accepted: 7 June 2021 / Published online: 14 July 2021

(c) The Author(s), under exclusive licence to Springer Nature Switzerland AG 2021

\begin{abstract}
\section{Introduction}

The modern-day athlete is often required to travel domestically and internationally including high-frequency short distances $(<3 \mathrm{~h})$ and low-frequency long distances $(>3 \mathrm{~h})$ that may involve the crossing of numerous time zones. The subsequent travel fatigue and jet lag experienced result in a myriad of shared symptoms, such as daytime fatigue, decreased concentration and alertness, sleep disruption and gastrointestinal disturbances $[1,2]$. These can lead to increased illness and injury risk as well as adverse effects on athletic performance [2-9].

Travel fatigue and jet lag are two distinct entities that may co-occur when travelling east or west across three or more time zones $[2,4,10-12]$. Travel fatigue occurs in all travelling athletes and can be acute following any individual long journey, or chronic (cumulative) as a consequence of
\end{abstract}

Athletes are increasingly required to travel domestically and internationally, often resulting in travel fatigue and jet lag. Despite considerable agreement that travel fatigue and jet lag can be a real and impactful issue for athletes regarding performance and risk of illness and injury, evidence on optimal assessment and management is lacking. Therefore 26 researchers and/or clinicians with knowledge in travel fatigue, jet lag and sleep in the sports setting, formed an expert panel to formalise a review and consensus document. This manuscript includes definitions of terminology commonly used in the field of circadian physiology, outlines basic information on the human circadian system and how it is affected by time-givers, discusses the causes and consequences of travel fatigue and jet lag, and provides consensus on recommendations for managing travel fatigue and jet lag in athletes. The lack of evidence restricts the strength of recommendations that are possible but the consensus group identified the fundamental principles and interventions to consider for both the assessment and management of travel fatigue and jet lag. These are summarised in travel toolboxes including strategies for pre-flight, during flight and post-flight. The consensus group also outlined specific steps to advance theory and practice in these areas.

Dina C. Janse van Rensburg

christa.jansevanrensburg@up.ac.za

Extended author information available on the last page of the article repetitive travel within a season $[4,10]$. It is a multi-domain disturbance that generally occurs with any travel regardless of the direction of travel or the number of time-zones crossed $[2,4,10,13]$. It is caused by the demands of travel itself, such as cramped conditions, prolonged mild hypoxia, changes in the external environment (trans-latitudinal travel i.e. winter-summer/summer-winter) and reduced physical activity [10]. Jet lag is episodic with similar but more severe and prolonged symptoms compared to travel fatigue and follows rapid travel across 3 or more time-zones (transmeridian travel i.e. east-west/west-east) [4, 10]. It is typically characterised by the desynchronisation between the internal human circadian system and the time at the new destination $[2,4,10,11,14]$. As a result, the circadian rhythm of several psychological, physiological and behavioural variables with a typical early morning nadir and late-afternoon peak is misaligned with the new local time. Depending on the training or competition time, this could directly affect athletic performance $[2,4,5]$.

Although the circadian system is well understood and described in the circadian physiology literature [5, 15-19], it remains difficult to translate and to apply this knowledge 


\section{Key Points}

Travelling athletes experience travel fatigue and jet lag that intensify their subjective burden and may influence performance and increase illness and injury risk.

Literature on management of travel fatigue and jet lag in athletes is limited. Based on physiological principles and laboratory-based studies, this review and consensus identified the most important interventions to counter.

Travel fatigue: maximise the amount of sleep obtained during travel.

Jet lag: maximise the rate at which the body clock adapts to the new time-zone, by following a guide that specifies $3 \mathrm{~h}$ periods of light exposure and avoidance.

Other useful interventions include:

Travel fatigue: plan meticulously, prevent illness, formulate hydration and food strategies.

Jet lag: preserve sleep, coincide exercise training with light exposure, adjust meal timing and composition, and sensible use of melatonin at the new destination.

Manipulating exposure to time-givers, e.g. light and exogenous melatonin, may aid in successful circadian re-alignment following travel in athletes. Conversely, inappropriate exposure may be counterproductive and cause detrimental side effects.

Reliable and repeatable multi-centre field studies, over longer durations and involving randomised allocation of potential therapeutic interventions are needed to advance theory and practice in these areas.

to travel management practice within sport. Research in this area is complex due to factors, such as inter-individual differences and the challenge of measuring the circadian phase in field studies, using markers, such as core body temperature (CBT) and melatonin. A recent systematic review on the management of travel fatigue and jet lag in athletes concluded that no evidence exists for specific travel fatigue interventions and that evidence for interventions targeting jet lag is of low quality [20].

Since evidence-based data underpinning travel fatigue and jet lag management are under-developed [3, 21], an expert panel was formed to define criteria from existing recommendations $[22,23]$, and to inform sport science and medicine practitioners and sport programme managers on current consensus-based recommendations from a practice-led perspective [24]. This paper aims to define the terminology commonly used in the field of circadian physiology; provide basic information on the human circadian system and how it is affected by time-givers (zeitgebers); discuss the causes and consequences of travel fatigue and jet lag; and provide consensus recommendations on managing travel fatigue and jet lag in athletes.

\section{Methods}

Our methodology is based on a recent publication, recommending specific criteria to reach consensus [23]. A lead group of three authors (CJvR, AJvR, PF) initially discussed the writing of a consensus document. A further 23 experienced researchers and clinical practitioners in the fields of travel fatigue, jet lag and sleep in the sports setting were invited to participate on the expert panel to formalise a consensus document and recommendations. The average experience of the authors in this field ranged from 4 to 25 years. The group consisted of 14 males and 12 females and embodied global representation from 11 different countries. Their expertise included 18 scientists (including sleep and circadian physiologists, sport scientists, a nutritionist and a statistician) and 8 medical team practitioners (medical doctors and physical therapists). The authors conducted comprehensive literature searches in PubMed, MEDLINE, CINAHL, Google Scholar, and SPORTDiscus to obtain relevant peer-reviewed publications regarding the human circadian system and the management of travel fatigue and/or jet lag. Two authors (CJvR, AJvR) compiled the first draft and sent it for initial comments by the full author group. The reviewed draft consisted of sections on terminology, the circadian system, travel fatigue and jet lag. According to preference, the authors chose primary working clusters from the four sections. Eight total Qualtrics surveys were sent for those sections where recommendations are provided, i.e. list of terminology (3), management options for travel fatigue (2) and management options for jet lag (3). A statistician (TC) analysed all feedback collected in the 8 surveys. To govern the threshold of agreement, only the statistician had access to the feedback provided by the authors.

The terminology group (AB, ID, TC) listed terms included in this consensus document that are commonly used to describe the human circadian system. The group provided three definitions for each term and administered a Qualtrics survey to systematically combine expert opinions and arrive at an informed group consensus on the selected terms. After the first round, a threshold of $80 \%$ agreement [23] was reached on the definitions of the following terms: biological night, chronobiotic, chronotype, circadian rhythm, jet lag, phase shift, phase response curve, re-entrainment, and suprachiasmatic nucleus. For the next round, the rest of the terms were included: body clock, core body temperature 
minimum (CBTmin), dim light melatonin onset (DLMO), internal desynchrony, melatonin, nadir, phase, process $\mathrm{C}$, process $\mathrm{S}$, retino-hypothalamic pathway, sedative (hypnotic), and zeitgebers (time-givers). For these terms, definitions with the least votes were excluded and the remaining two definitions were adapted according to comments suggested by the authors. In the 3rd round, the senior author group (CJvR, AJvR, PF) based consensus on the majority vote since authors could not agree on phrasing the definition of terms. Further comments from all authors were applied to reach the final definition for each term.

The circadian system group (DS, MD) summarised and documented relevant literature on the physiological, psychological and behavioural variables of the human circadian system. They focussed on the relevance to translate theory into practice.

The travel fatigue group $(\mathrm{KoS}, \mathrm{ACS}, \mathrm{JV}, \mathrm{KM}, \mathrm{MB}, \mathrm{ML}$, $\mathrm{MN}, \mathrm{SH}$ ) summarised current literature regarding the causes and consequences of travel fatigue. This group also listed potential management options based on available literature including current opinions, expert recommendations and research-based studies (laboratory and field) on the management of travel fatigue. All authors voted on the inclusion or exclusion of each management option. Consensus was reached after the 2nd Qualtrics survey. A threshold of $80 \%$ agreement [23] was used to indicate a consensus among the authors. The average response rate by the author group to reach consensus was $96.2 \%$.

The jet lag group (HF, ACS, CS, GV, GR, JMA, LG, MS, MDo, RC, TP) summarised current literature regarding the causes and consequences of jet lag. This group listed potential management options based on available literature including current opinions, expert recommendations as well as research-based studies (laboratory and field) on the management of jet lag. All authors voted on the inclusion or exclusion of each management option using a Qualtrics survey. After three rounds of Qualtrics surveys, consensus was reached. A threshold of 75\% agreement [23] to each survey was used to indicate consensus among the authors. The average response rate by the author group to reach consensus was $92.3 \%$.

Each sub-group within the consensus group provided sections on their relevant topics to form a second draft. The lead group (CJvR, AJvR, PF) reviewed and collated the different sections into a third draft. The author group collectively revised this third draft. Extensive discussions by all members of the consensus group followed, and all authors provided comments and suggestions. The lead group accepted or declined all responses within reason and sent the 4th draft for another round of input from the author group. Subsequently, all authors of the consensus group reviewed and approved the final manuscript.

\section{Terminology}

Terminology in the field of circadian physiology is complex. The following detailed explanations in Table 1 were developed by consensus and is an overview of specific terms and phrases commonly used when (a) referring to the human circadian system, or (b) when practitioners are contributing to travel planning and intervention design.

Although well described in the literature of circadian physiology, the information on the human circadian system is very detailed and beyond the scope of time-poor practitioners. The section below provides relevant information to aid practitioners to translate and apply circadian physiology into practical travel management.

\section{Circadian System}

The circadian system regulates the diurnal cyclical rhythms exhibited by physiological, psychological, and behavioural processes of the body over approximately $24 \mathrm{~h}[35,36]$. This system is regulated by a central "master clock", the suprachiasmatic nucleus ( $\mathrm{SCN}$ ), as well as peripheral clocks located in almost every cell of the body [16-18]. These are synchronised by a sophisticated system of neuronal, hormonal and autonomous signalling [13]. Output signals from the clocks are subsequently generated, influencing physiological, psychological and behavioural processes [15]. The master and peripheral clocks of the circadian system synchronise through zeitgebers or time-givers [37].

\subsection{Time-Givers/Zeitgebers}

Common time-givers are light, sleep-wake transition, physical activity, social cues and meals [38, 39]. Light is arguably the most critical time-giver, as photic stimuli, via the retino-hypothalamic pathway, stimulates or inhibits the SCN $[13,15,16,18]$. The timing, intensity, duration and spectral composition of light appear to be the most critical factors in altering the timing of the circadian system [13, 27] (Fig. 1).

\subsection{Phase Markers}

Key players in successful circadian re-alignment are the phase markers melatonin and CBTmin. Melatonin is a hormone secreted by the pineal gland that aids in the process to consolidate sleep. The onset of secretion under dim light conditions, termed dim light melatonin onset (DLMO), occurs $\sim 2 \mathrm{~h}$ before habitual bedtime and aligns with the start of the biological night [15-18]. The circadian rhythm of CBT oscillates $~ 0.8-1.0^{\circ} \mathrm{C}$ between a night-time minimum and a daytime maximum in a rhythmic 24-h pattern [42, 43], with CBTmin typically occurring between 03:00 and 07:00 [44, 45]. 
Table 1 Terminology of specific terms and phrases of the human circadian system [2, 5, 13, 15-18, 25-34]

\section{Biological night}

Body clock

\section{Chronobiotic}

Chronotype

\section{Circadian rhythm}

Core body temperature minimum (CBTmin)

Desynchronisation

Dim light melatonin onset (DLMO)

Jet lag

\section{Melatonin}

Nadir

Phase

Phase-shift

\section{Process C}

\section{Process S}

Phase response curve (PRC)

\section{Re-entrainment}

\section{Retino-hypothalamic pathway}

Sedative (hypnotic)

\section{Sleep banking}

Sleep window
The internal circadian time of diurnal species when melatonin is secreted, core body temperature drops, and sleep propensity increases

The body's internal rhythms last approximately $24 \mathrm{~h}$ and are controlled by the suprachiasmatic nucleus (master clock) which helps to regulate daily cycles of sleeping, wakefulness, and eating, etc.

A substance that adjusts the phase and period of the internal biological rhythms (circadian rhythm) of an individual

The tendency for someone to be a morning-type, an intermediate-type or an evening-type person with a preference to sleep at a specific time as determined by genetics (e.g. Per3 allele), environmental, and age-related factors

An internally generated biological cycle or rhythm of physiological processes recurring naturally in the absence of time-givers lasting approximately $24 \mathrm{~h}$, that can be modulated by external timegivers. The term is derived from "circa diem" meaning "approximately a day"

Daily low point (i.e. trough or nadir) of the circadian rhythm of core body temperature that correlates with the lowest levels of alertness

A misalignment (desynchronisation) between the body's endogenous circadian system and the light-dark cycle (external environment)

The time of the daily onset of melatonin production by the pineal gland located in the base of the brain. Typically, DLMO occurs $\sim 2 \mathrm{~h}$ before habitual sleep onset under dim light conditions. Dim light refers to the requirement to assess melatonin levels in low light $(<101 \mathrm{x})$ as its production is suppressed by light (i.e. > $10 \mathrm{~lx}$ )

Temporary impairment of sleep and wakefulness, as well as other biological functions, associated with rapid eastward or westward travel across 3 or more time-zones

Endogenous melatonin: The darkness hormone which consolidates sleep and is produced predominantly by the pineal gland (melatonin synthesis and secretion is controlled by the suprachiasmatic nucleus)

Exogenous melatonin: A synthetic substance that can induce sleepiness and/or shift the timing of the circadian system to help alleviate the symptoms of jet lag and support synchronisation of sleep and wake patterns to a new time-zone

Minimum or trough of a rhythm or time series; often the minimum of a fitted curve (rather than the absolute minimum) of a physiological or behavioural rhythm

A specific time or point within a circadian rhythm

A shift in a circadian rhythm (phase-advance or phase-delay)

- Phase delay: After a westward flight, the body clock is ahead of time (i.e. at a later time of day) compared to the destination time zone and has to delay or move backward (to an earlier time of day) to become synchronised

- Phase advance: After an eastward flight, the body clock is behind (i.e. at an earlier time of day) compared to the destination time zone and must advance or move forward (to a later time of day) to become synchronised

The circadian process coordinating with the light-dark cycle and involved in regulating sleepwake cycles

The homeostatic sleep pressure system that is regulated by adenosine, which accumulates with wakefulness and dissipates with sleep

A curve or wave illustrating the magnitude of phase shift of the circadian clock between a stimulus and a response (advance or delay) induced by exposure to a time-giver (e.g. bright light) at various times of day or night

Re-alignment of the endogenous circadian system with the timing of the external environmentresulting in both oscillations having the same frequency

A photic reception pathway between the retina and master clock in the suprachiasmatic nucleus, activated by light, to coordinate circadian rhythms with the solar day

A drug that suppresses the central nervous system function. It is often referred to as a sleeping pill or a tranquiliser. Its effects range from promoting sleep to reducing anxiety. Adverse effects include lethargy, impaired alertness, etc. Prescription and consumption only on doctor's orders

To extend sleep beyond normal amounts in order to have a surplus of sleep during sleep deprivation periods (e.g. travel) or when optimal performance is needed

The interval of time when someone is able to sleep and is partly driven by both homeostatic and circadian processes 
Table 1 (continued)

Suprachiasmatic nucleus (SCN)

Zeitgebers

(Time-givers)
The master clock of the human circadian system which helps synchronise rhythms of physiology and behaviour. It consists of small nuclei in the hypothalamus of the brain, above the optic chiasm and receives external phase information via specialised light-sensitive cells in the retina

The cues (physiological, psychological, behavioural, pharmacological and environmental) that entrain the phase of a biological rhythm, also known as time-givers or timing cues or synchronisers

\subsection{Sleep Regulation}

When CBT is at its lowest or is falling rapidly, it is easier to initiate sleep, whereas it is difficult to sleep when CBT is high or rising rapidly $[2,46]$. Internal physiological changes that occur due to the circadian system also play an important role in initiating sleep. As sleep homeostasis/sleep pressure commonly referred to as Process S, accumulates with increasing waking hours of sleep, circadian-induced secretion of melatonin along with reductions in CBT and blood pressure, known as Process $\mathrm{C}$ allows a person to sleep [32]. Misalignment between these processes often leads to sleep disruption, including difficulty initiating and/or maintaining sleep [32].

\subsection{Phase-Shift}

Exposure to a time-giver induces a wave response and can shift the circadian system (phase-advance or phase-delay). The strength of the shift is often described using a phase response curve (PRC). Light exposure during the $0-6 \mathrm{~h}$ period on either side of the CBTmin is effective but $0-3 \mathrm{~h}$ results in maximum phase shifts [47-49]. Although the dose-response relationship is non-linear, the wavelength (shorter blue light, 400-495 nm) and intensity of bright light ( $\geq 2500 \mathrm{~lx})[50,51]$, and the duration of exposure (longer) will determine the degree to which the timing of the circadian system can be shifted [52-54]. The pattern of endogenous melatonin secretion is inversely related to body temperature-peak melatonin secretion occurs at the nadir of CBT (Fig. 2) [55]. Manipulating exposure to timegivers (Fig. 1) may aid in successful circadian re-alignment mitigating the effects of jet lag. Conversely, inappropriate exposure may be counter-productive and cause detrimental side effects. An example of this is evidenced by the impact of irregular exposure to bright light leading to cognitive deficits and mood alterations [56].

\subsection{Individual Differences}

Re-entrainment following a time-zone change is believed to also depend on an individual's chronotype [13, 19, 58]. Hypothetically, the population consists of 3 chronotypes: morning-type- (18-30\%), intermediate-type- (50-60\%) and evening-type individuals (18-20\%) [19, 59]. Currently, evidence to support links between chronotype and jet lag symptoms is based on social jet lag and shift worker studies [60-63]. To assist practitioners in understanding their travelling athlete, and help individualise scheduled intervention (e.g. light therapy), please refer to the advice presented online in Electronic Supplementary Material Table S1: morning-type subjects vs. evening-type subjects $[2,13$, 19, 58-69]. Additionally, genetic differences regarding reentrainment are of potential interest. Specifically, within the Period (PER) gene family, the $P E R 3^{4}$ allele is associated with extreme evening-type, whereas the $P E R 3^{5}$ allele is associated with extreme morning-type [69].

\section{The Concept and Relationship Between Travel Fatigue and Jet Lag}

Travel fatigue is a multi-domain disturbance that can be either acute or cumulative due to repetitive travel over a season, regardless of the mode of transport (road, rail, plane), the travel direction or the number of time zones crossed $[2,4,10,13]$. Jet lag follows any journey rapidly crossing three or more time-zones, is episodic and implies full recovery after resynchronisation [2, 4, 10-12]. The relationship between travel fatigue and jet lag is conceptualised in (Fig. 3) and further discussed in Sects. 6 and 7.

\section{Travel Fatigue}

\subsection{Causes and Consequences}

Travel fatigue refers to exhaustion and tiredness associated with any long journey $[4,70,71]$ following trans-latitudinal travel (north-south/south-north) or transmeridian travel. It is a complex summation of physical, physiological and psychological factors that accrue during an individual trip $[4,9]$, and could accumulate over a competition season. At present, there is substantial anecdotal evidence of its prevalence $[4,9,61,72-74]$. There is however a lack of empirical evidence of the mechanisms underpinning travel fatigue, and how it might be prevented or its impact lessened [20]. Some 


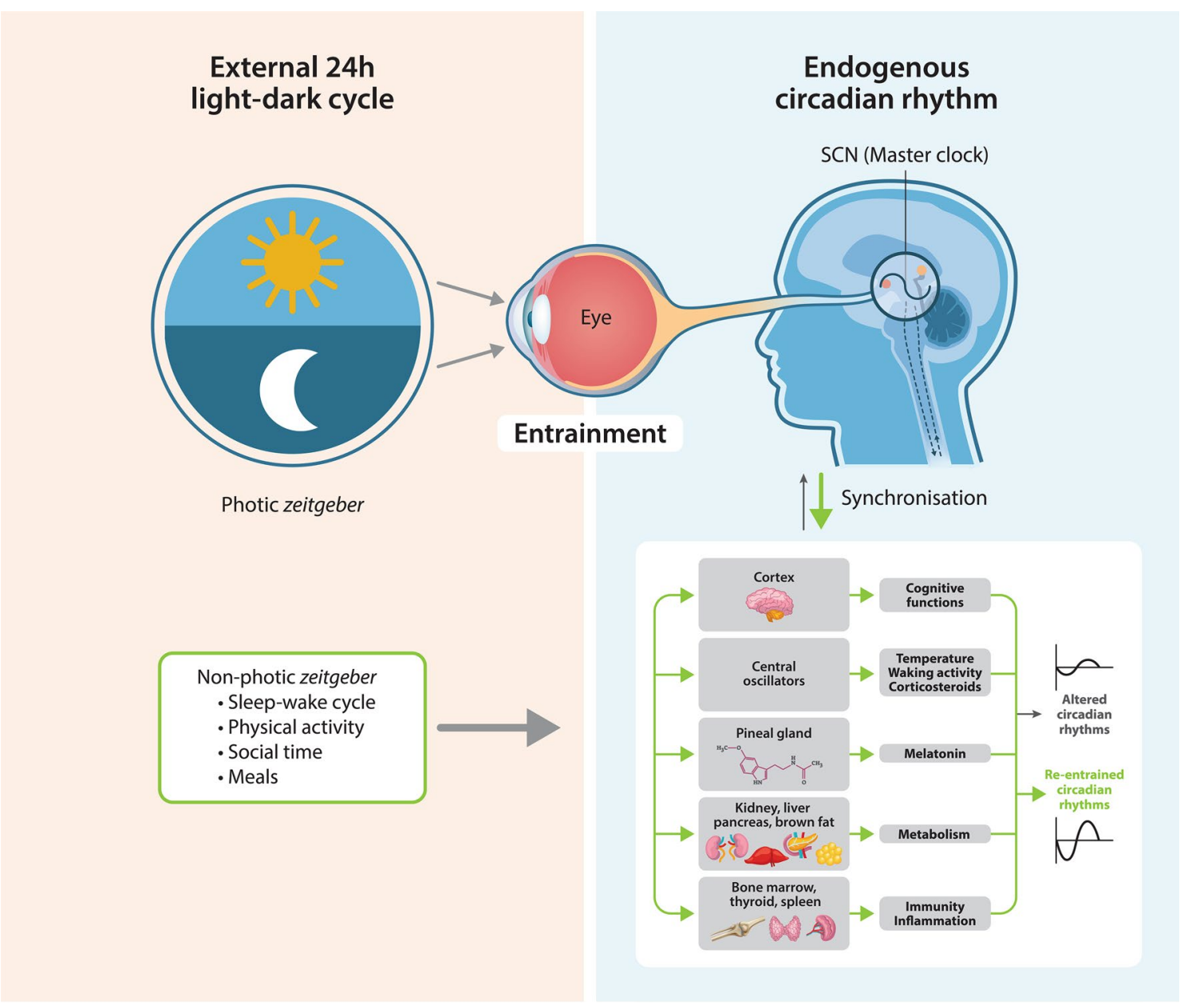

Fig. 1 Schematic diagram of the circadian clock entrainment pathways. Light directly entrains the suprachiasmatic nucleus (SCN), whereas other non-photic zeitgebers exhibit rhythmic changes and entrain the SCN and peripheral clocks throughout $24 \mathrm{~h}$-adapted with permission from Buttgereit et al. [40] and Hood and Amir [41] commonly perceived contributors to travel fatigue are highlighted in Fig. 3 and Table 2.

When discussing the burden of travel fatigue on athletes, there are four key factors to consider: the total distance travelled, the time of travel (am or pm), the frequency of travel, and the length of the season. This concept is also referred to as the "recovery window" and indicates the available time for recovery (Fig. 3). The first three factors are welldocumented in some professional sports [83, 86, 87]. For example, the National Basketball Association's (NBA) regular season continues over 6 months consisting of 41 home games and 41 away games often inclusive of back-to-back games [87]. Congested schedules often include large travel distances as experienced by teams within the 4 top professional leagues [i.e. the National Hockey League (NHL),
Major League Baseball (MLB), National Football League (NFL), and the NBA] in the United States entailing travel between 40,000 km (once around the world) and 80,000 km (twice around the world) per season [88].

There is limited evidence on the potential consequences of travel fatigue. Studies have assessed the acute effects of air travel without crossing time zones on performance and perceptual measures among team sports players [6-9]. Overall, under these circumstances, travel has no noticeable effect on indicators of performance (i.e. technical and tactical performance during competition; countermovement jump performance; Yo-Yo intermittent recovery test performance), but negatively influences perceptual measures (e.g. reduced alertness, motivation and mood, increased perceived stress and fatigue) $[4,6-9]$. 


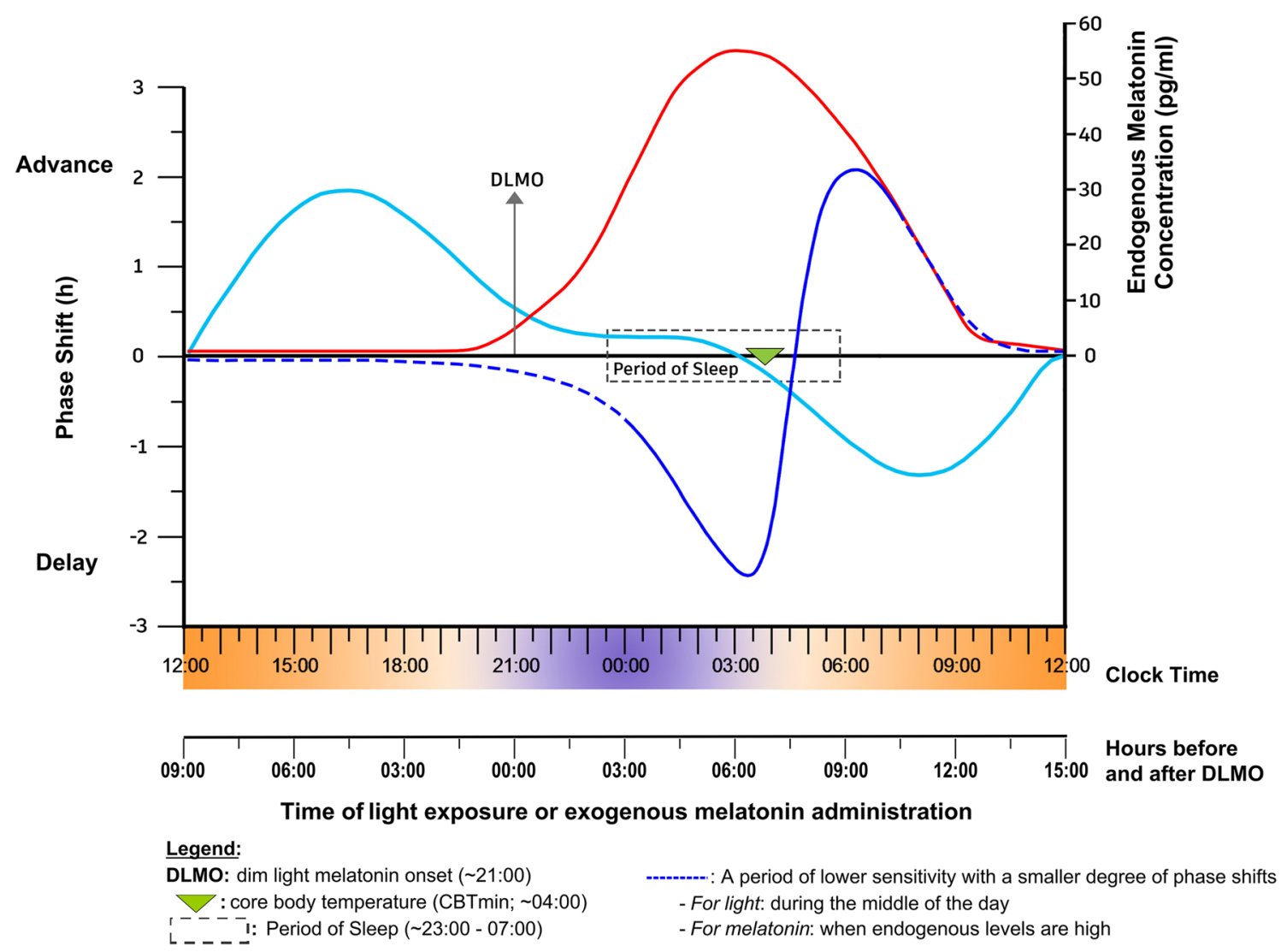

Fig. 2 Normal profile of endogenous melatonin (red line) and schematic human phase response curves to light (dark blue line) and exogenous melatonin (light blue line). The $y$-axis on the right shows the endogenous melatonin concentration. The $y$-axis on the left shows the direction and relative magnitude of the phase shift following light

\subsection{Assessment of Teams and Athletes}

Athlete monitoring tools may help to understand both acute and chronic travel fatigue in athletes. In this respect, the creation and validation of a travel fatigue scale would improve understanding of the travelling effect [72] and should target measurement of the main symptoms of travel fatigue, namely persistent fatigue, recurrent illness, behaviour and mood changes and loss of motivation. An ideal tool should detect a significant part of travel fatigue including travel, sport, personal, social and seasonal factors and also provide scores for both individual trips and accumulative travel fatigue over a season (repeated measures design). Additionally, the coefficient of variation between different assessments of the same athlete should be small in comparison with the difference between athletes. Finally, its levels should not vary significantly in the same athletes under the same conditions at different times. As this is a highly individualised measurement, it should be used primarily to detect intra-individual changes. Travel fatigue is multifactorial and exposure or exogenous melatonin administration at various times as presented on the $x$-axis. The magnitude of phase shifts will depend on the dosage used and should not be directly compared - adapted with permission from Eastman and Burgess [5] and Burgess et al. [57]

presently no single marker quantifies all these requirements. Surrogate markers for travel fatigue must include subjective ratings of sleep quality, stress/mood, fatigue, and recovery [89]. Current recommended tools include the Total Quality of Recovery Scale [90] to measure psychophysiological recovery (i.e. mood states and body signals, such as sensations of soreness or heaviness), the Daily Analysis of Life Demands for Athletes Questionnaire and the Acute Recovery Stress Scale [91], which are also practical and intelligible measures that can be used to monitor general changes in fatigue and recovery states [92]. Athletes must be thoroughly familiarised with these perceptual rating scales in order to benefit. Notably, travel fatigue-specific assessments would only be used in a scenario where jet lag is not a problem (e.g. teams competing in the UEFA European Football Championship), as there is shared symptomatology and it is difficult to separate out the fatigue caused by the travel itself. It is also important to take into account that too many different psychometric tools will add to the daily burden on athletes and may lead to superficial feedback. 

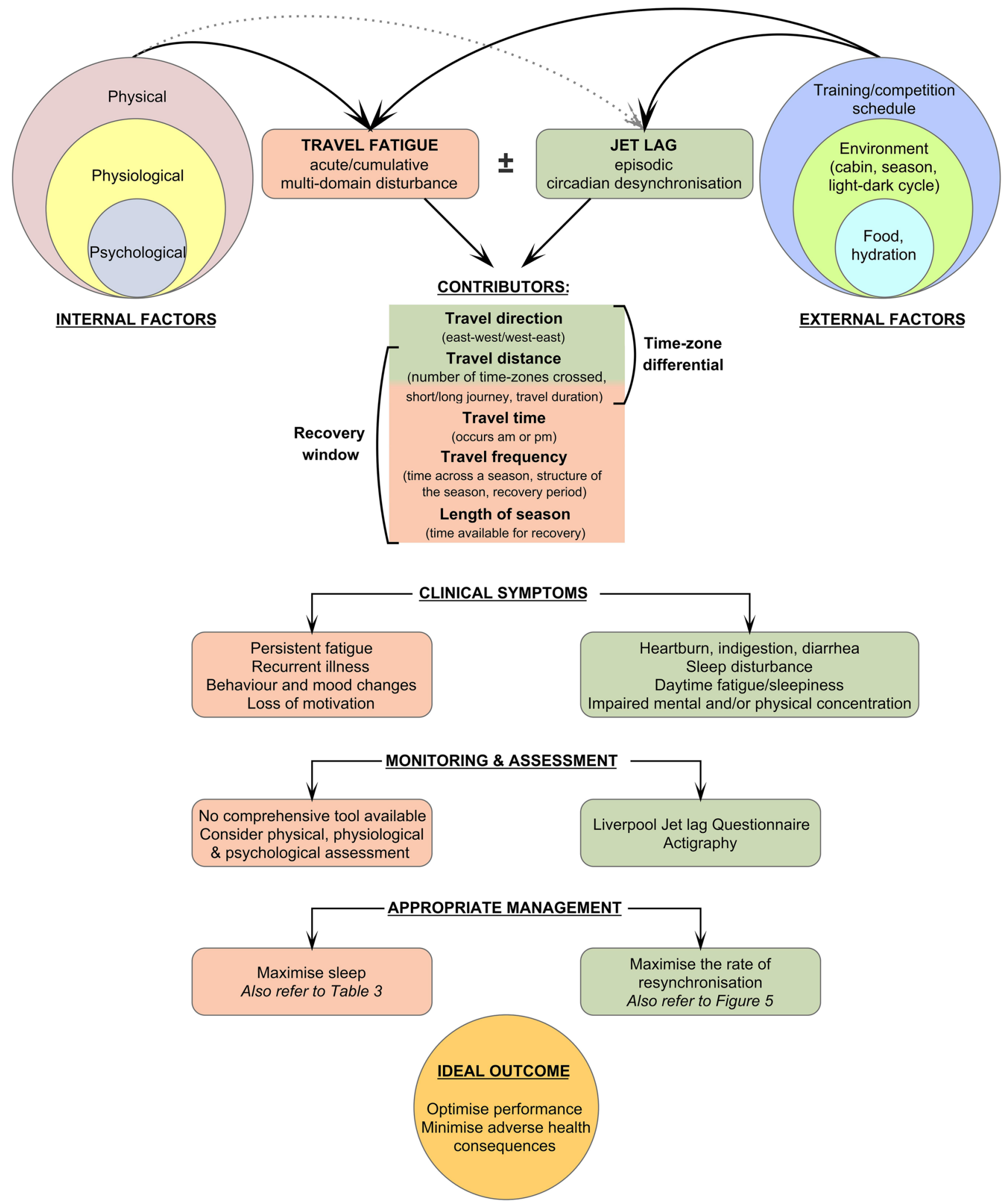

Fig. 3 A proposed multifactorial model of travel fatigue and jet lag-adapted with permission from Samuels [4]. Travel fatigue (on the left) is influenced by both internal and external factors. Allowing a recovery window taking into account travel distance, travel time, travel frequency and the length of the season combined with monitoring and appropriate management will lead to the ideal outcome. Jet lag (on the right) is also influenced by external factors and less so by internal factors. Travel direction and travel distance, specifically the number of time zones crossed will affect the severity experienced by the individual. Recovery to achieve the ideal outcome relies on resynchronisation of the body clock 
Table 2 Possible physical, physiological, psychological contributors to travel fatigue [4, 9, 14, 20, 61, 70-85]

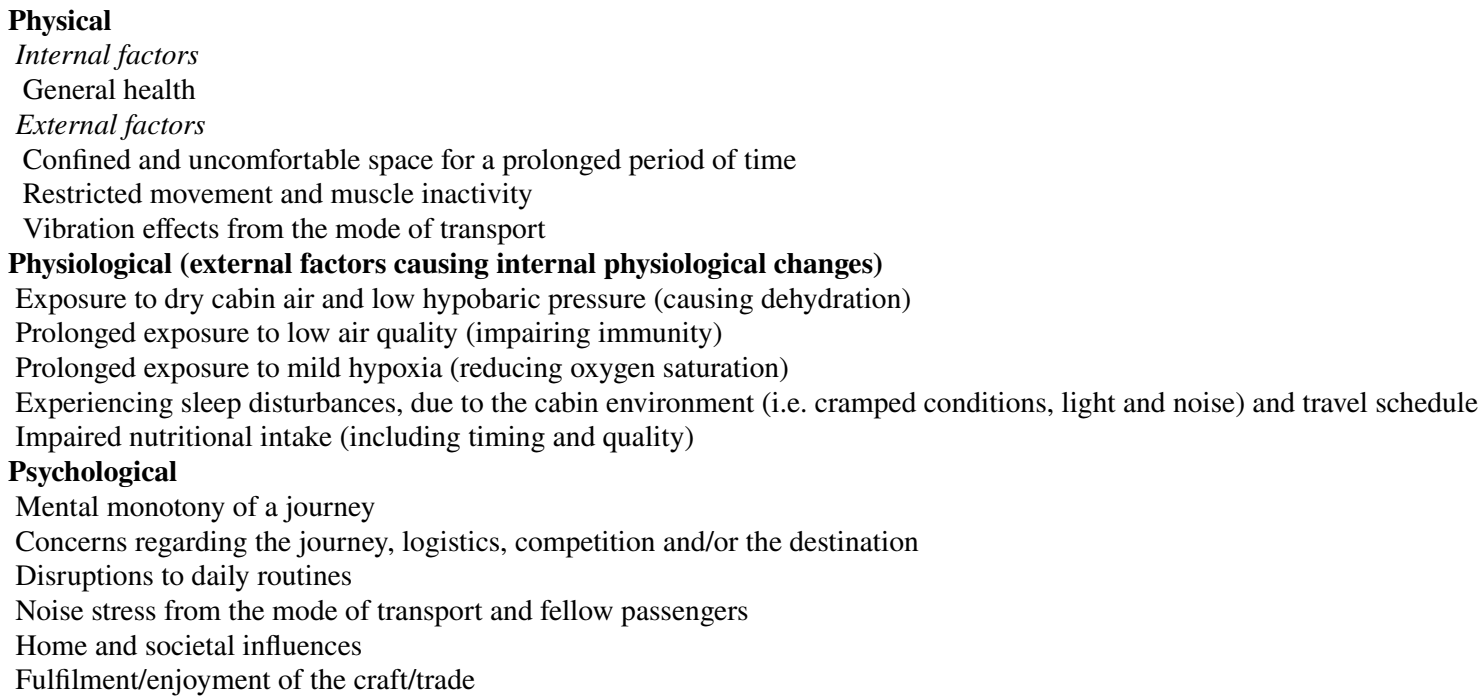

\subsection{Current Recommendations in the Management of Travel Fatigue}

A recent systematic review reported that no research exists on interventions that specifically manage travel fatigue in athletes [20] with available studies limited to opinions and collective experience rather than original research [93]. While travel distance or duration may be the key factor in the magnitude of travel fatigue experienced, having an adequate period to recover from travel (e.g. a recovery window) to prepare for training or competition is critical [4] and should be accounted for in travel arrangements. This may be unfeasible for athletes that travel frequently. Hence, they may need to implement interventions before and during travel to reduce fatigue (e.g. protecting sleep) or to treat fatigue post-travel (e.g. utilising napping and caffeine) $[4,94]$. Following consensus, the information discussed in Table 3 was determined valuable for the management of travel fatigue.

\section{Jet Lag}

\subsection{Causes and Consequences}

\subsubsection{Causes}

The concept of "time-zone differential" relies on the function of distance travelled, i.e. travel duration and number of time-zones crossed as well as the travel direction. It is a circadian phenomenon specifically relating to jet lag [4] (Fig. 3). After rapid transmeridian travel (air travel across 3 or more time-zones) or trans-latitudinal travel including crossing of three or more time zones, the circadian system cannot immediately adjust to the light-dark cycle in the new time zone. This causes internal desynchrony, between both the master and peripheral clocks [2], as well as with sleep homeostasis [5, 104]. As a result, the circadian system remains aligned, at least initially, with the timing of the light-dark cycle in the departure time zone rather than the arrival time zone [105]. The circadian system must be re-entrained, whereby the internal clocks resynchronise with external time-givers (Fig. 2) [17, 18], over several days [2]. As a rule of thumb, the duration of natural alignment is 0.5 days per time-zone crossed in a westerly direction, i.e. $2 \mathrm{~h}$ per day, and 1 day per time zone crossed in an easterly direction, i.e. $1 \mathrm{~h}$ per day $[5,57]$. Until re-entrainment is complete, the physiological and psychological systems that are regulated by the circadian system (e.g. digestion, sleep, or mood) will remain misaligned with the new local time, and depending on time of training or competition, this may impact performance $[2,5,9,21]$.

\subsubsection{Consequences}

The most common symptoms of jet lag are gastrointestinal discomfort, daytime fatigue/sleepiness, impaired mental or physical performance and poor sleep [71, 106]. The intensity and duration of jet lag symptoms worsen with an increasing number of time zones crossed, i.e. crossing 3-4 time zones produces milder symptoms compared to crossing 10-12 time zones [106]. The experience of jet lag is also greatly influenced by the direction of travel [5]. For example, after a westward flight over 8 time zones, athletes will feel sleepy, their performance will be impaired in the evening, and they will wake earlier than usual in the morning [21]. In contrast, after an eastward flight over 8 time zones, athletes will also 
Table 3 Important information to consider in the application of travel fatigue management [2, 4, 82, 93-103]

\section{Pre-travel}

Sleep

Protect sleep as much as possible

Be well-rested before travel (e.g. sleep banking strategy)

If sleep deprived avoid aiming to catch up on sleep during travel

Planning

Start as soon as destinations and dates of sporting events are known

Identify optimal travel options (flights, rail or bus) in terms of departure and arrival times, the flow-through security, venues for eating, availability of lounges

Calculate the total travel duration and stopover durations

Minimise time between last "proper" sleep at the place of departure and first "proper" sleep at the destination

Provide exact schedules and individual responsibilities to athletes and management in advance of travel

Ensure all documentation is in order

Training synchronisation

Plan training load and intensity before travel to allow for expected relative rest associated with travel

Illness prevention

Ensure vaccinations are up to date

Treat recurrent illnesses

Pack prefilled WADA-approved prescription medication

Replace long duration, high volume training which can be immuno-suppressive with shorter duration, high intensity sessions

Refuel and rehydrate

Implement an evidence-based nutrition and hydration plan to meet macro- and micro-nutrient needs as well as fluid needs well in advance of travel

Focus on electrolyte replacement is required for a minority of athletes e.g. "salty sweaters", nutrient deficiencies, etc. as electrolyte needs should be covered for the majority of athletes following recommended nutrition and hydration guidelines

Check food availability during the trip

Pack non-perishables (check customs regulations)

Plan catering, eating-out, and self-catering options at destination ahead of time

Vet dietary supplements (risk of prohibited substances, illegal substances, ingredient interactions or side effects) that could be counter-productive to travel, sleep or performance goals

\section{During travel}

Sleep

Take naps when appropriate

Utilise eye-masks, earplugs or noise-cancelling headphones and/or pillows

Do not allow screen time to interfere with napping or sleeping

Maximise angle of recline

Compression

Wear medical-grade compression and comfortable clothing

Illness prevention

Early management of illness and/or motion sickness

Avoid touching areas commonly infested with micro-organisms (e.g. tray tables, chair headrest, etc.); frequently wipe these areas clean

Adhere to guidelines to prevent the spread of illness (e.g. coronavirus disease (COVID-19) guidelines)

Refuel and rehydrate

Follow a hydration plan configured pre-travel; regular sips of non-alcoholic and non-carbonated drinks; water (best), fruit juice, or carbohydrate-containing drinks based on individual energy/caloric needsAvoid caffeinated beverages and foods at least $\pm 6 \mathrm{~h}$ before bed or sleep time Avoid alcohol completely

Consume regular but smaller meals, nutritious fibre-rich snacks (fresh or dried fruit, high-fibre crackers, energy bars, trail-mix), avoid calorieoverload (stick to the plan, limit "mindless grazing" on calorie-dense snacks (such as potato crisps, chocolates, ice cream, pies, high-fat energy bars, greasy foods)

Food hygiene is essential (sanitise hands regularly, eat non-perishable, or freshly prepared foods, keep hot foods hot, keep cold foods cold)

Stopovers

Move frequently

Stretch

Walk around

Get fresh air 
Table 3 (continued)

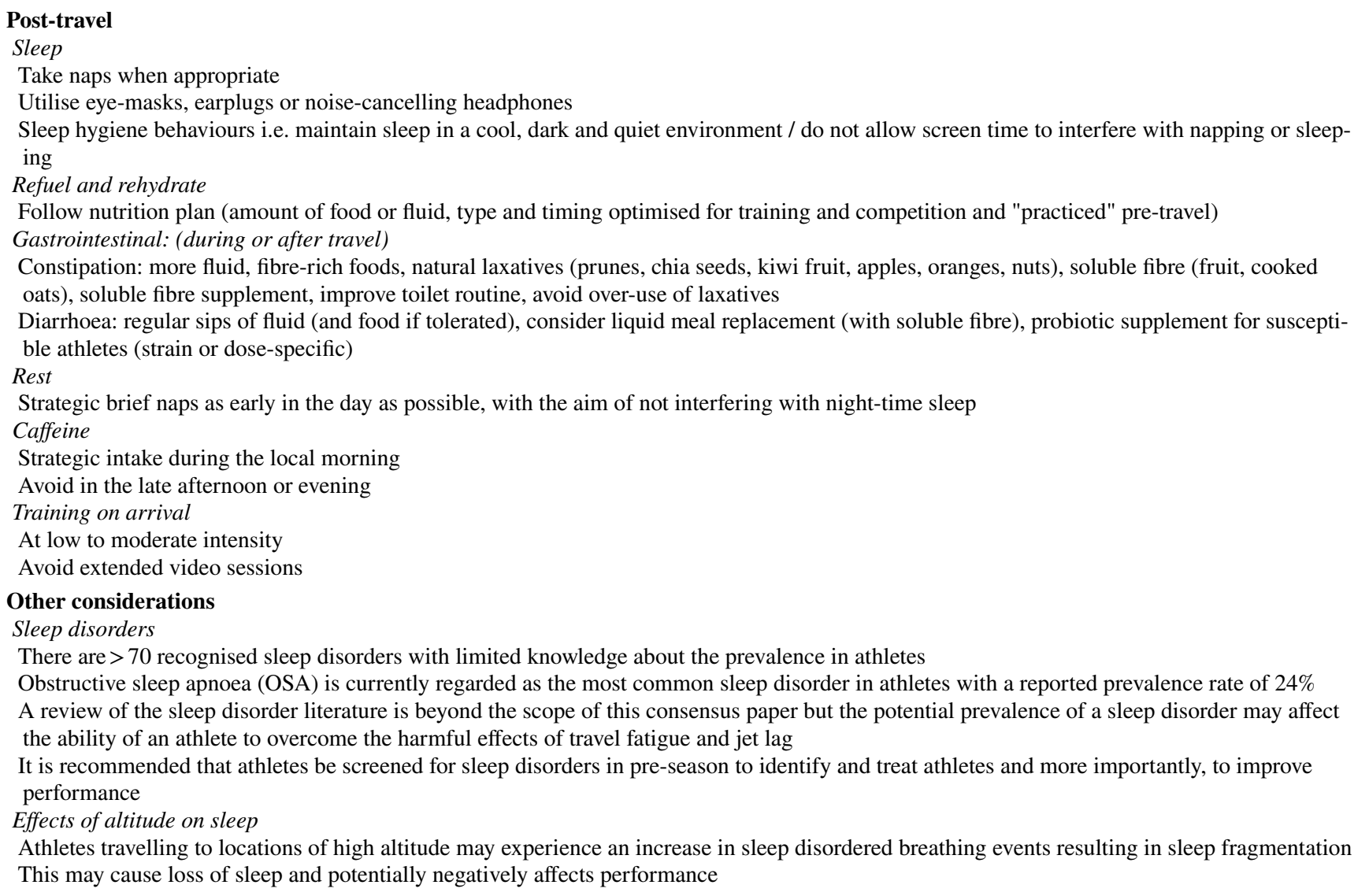

feel sleepy, but their performance will be impaired in the early afternoon, they will have difficulty falling asleep at their regular bedtime, and they will sleep in later than usual [21]. Chronotype may also influence these responses as morning larks adapt better to eastward travel (easier to shift circadian rhythms earlier), whereas night owls adapt better to westward travel (easier to shift circadian rhythms later) [62].

\subsection{Assessment of Teams and Athletes}

Given the complexity of the disruption to the circadian system, as well as the variety of associated physiological and psychological symptoms, several assessment tools can be used to assess the different aspects of jet lag. These may include questionnaires, sleep diaries in conjunction with actigraphy and circadian-phase markers.

Of the available questionnaires, the Liverpool Jet Lag Questionnaire appears to be the most valid and reliable subjective tool $[74,107]$. This questionnaire is a visual analogue scale with 15 subjective ratings about overall perceived jet lag and its symptoms (sleep, fatigue, appetite, mental performance and bowel function), measured at different times of the day. Other tools such as the Columbian Jet Lag Scale [108] may offer suitable alternatives [109].

Actigraphy typically utilises movement-derived algorithms to provide estimates of sleep timing, duration and quality, and is commonly used in athletic settings in conjunction with sleep diaries $[110,111]$. While actigraphy can help with information regarding rest-activity and/or sleep behaviour during travel, there is minimal evidence to support its use in evaluating jet lag per se. Circadian-phase markers perhaps represent the most accurate objective measure to assess jet lag, as they examine a phase response to interventions (e.g. CBT, salivary melatonin,[48, 112] body skin temperature) $[13,113,114]$ but are unlikely suitable for sport due to the practicality, cost and invasiveness. If feasible, these circadian-phase markers could give insight into designing optimal jet lag interventions. A technique to indicate if sleep-wake behaviour has adapted is to measure the change in the mid-point of the sleep period between home and destination time zone, i.e. the difference in the median hours between bedtime and get-up time as assessed by actigraphy $[60,115]$. The authors suggest this as a possible alternative to measuring CBT and salivary melatonin-phase markers.

There are several online jet lag calculators and mobile applications which provide advice on the timing of 
interventions to theoretically help adjust to a new time-zone [116-118]. In the elite sport environment, these calculators and mobile applications still require validation of the scientific base used to provide this advice, i.e. how is circadian phase determined, and are the proposed interventions evidence-based [119]. The consensus group cautions against the use of these until further research examining the efficacy and effectiveness of these tools in the athlete environment has been conducted.

Choosing measures to assess jet lag depends on a range of factors, such as the intention of the measure, validity and reliability, suitability for laboratory or field testing, as well as cost, time, practicality and expertise of operation. Teams or athletes are best served to select a tool that serves their direct purpose. Further research is needed to determine appropriate assessment measures of jet lag for teams and athletes $[20,120]$.

\subsection{Current Recommendations in the Management of Jet Lag}

Most literature refers to light, melatonin and preservation of sleep as the best options to mitigate jet lag. Considering the impact of sleep loss on performance, one of the main goals taking into account the athlete's training and competition schedules, should be to preserve sleep. Other strategies include exercise, nutrition, melatonin analogues, sedatives and stimulants. The literature regarding recommendations on management strategies is published mainly as opinions $[4,13,93,106]$, collective experience manuscripts $[3,5,21$, 121], laboratory research studies on how to induce a phase shift [122-125] and laboratory research studies on how to recover from a phase shift $[20,48,49]$. Considering the literature referenced in this consensus paper, extrapolating evidence from healthy community and military populations and following the findings of a recent systematic review [20], the author group collectively summarised current recommendations based on consensus (Table 4, Figs. 4, 5 and 6).

\section{Theoretical Concepts to Guide Future Research}

To address the gaps in knowledge, high-quality multi-centre research that is repeatable and reliable is required in athletes, and utilising multi-disciplinary methodology in an attempt to adopt a holistic approach [146]. Specific measurements are required [e.g. CBT, melatonin, electroencephalogram (EEG)] otherwise the "research" will continue to either be surrogate measures, opinions or collective experiences.

For travel fatigue, randomised trials and longitudinal studies are needed to compare interventions aiming to reduce travel fatigue. Cabin conditions including seat size in buses, trains and planes can contribute to travel fatigue and require more research. The impact of specific parameters related to air travel, such as the average flight altitude, and the frequency and magnitude of atmospheric pressure, changes during the flight, which affects air cabin oxygen saturation levels are also worth exploring. Additionally, information on how travel fatigue is impacted following short distance $(<3 \mathrm{~h})$ vs. long distance $(>3 \mathrm{~h})$ travel, as well as the direction of travel (north-south/south-north, east-west/west-east) and the frequency of travel across a season is required. From a different perspective, there may be value in qualitative research evaluating how much athletes, coaches and support staff value and use monitoring tools. Determining the specific intervention, and the reason why coaches and athletes utilise these to minimise travel fatigue is also important. This is significant considering the burden which can be associated with athlete monitoring, the role of coaches and support staff in interpreting such data, concerns about whether such data are used in a meaningful manner, and the importance of athlete psychological health in perceived fatigue [147].

Well-controlled field-based jet lag studies that examine circadian adaptation and the impact of light exposure or avoidance schedules, using an appropriate phase marker, are required. To better understand risk factors and develop at-risk profiles for suitable interventions aligned to these profiles, tools to predict jet lag symptom severity and chronicity in individual travelling athletes need to be developed. Multi-centre studies exploring travel across a season, in competitions that involve frequent transmeridian travel (e.g. World Rugby 7 Series) rather than just assessing the impact of once-off travel will be valuable. Polysomnography (PSG) baseline data in more sports, sexes and age groups may be useful to identify sleep disorders in athletes and those who may be more at risk when travelling and also to compare PSG data on return to home to assess how long it takes for sleep to normalise.

\section{Conclusion}

This review and consensus statement highlights the complexity and lack of empirical research surrounding the measurement and management of travel fatigue and jet lag in athletes, curtailing the provision of strong recommendations. It concurs that travel fatigue and jet lag can inflict real and impactful issues on athletes regarding their performance and risk of illness or injury. Considering strategies pre-flight, during flight and after arrival at the destination, experts working in the field reached consensus on the management of travel fatigue and jet lag in athletes. Travel toolboxes covering fundamental principles and expert consensus recommendation for interventions are provided. Key interventions 
Table 4 Essential information to manage jet lag [3-5, 13, 20, 21, 48, 49, 93, 106, 121-127]

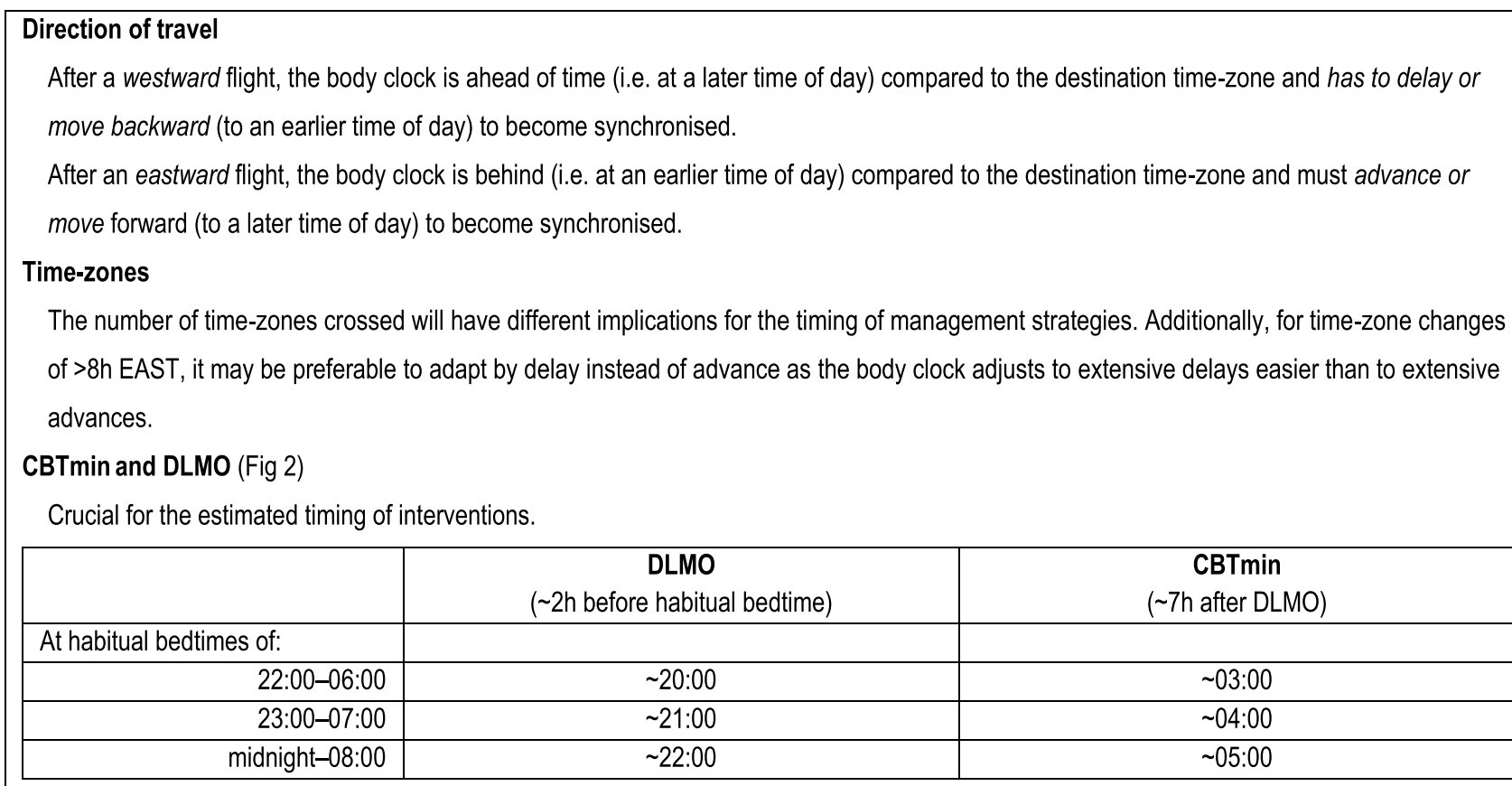

\begin{tabular}{|l|c|c|}
\hline To calculate CBTmin & $\boldsymbol{f}$ travelling WEST & H travelling EAST \\
\hline & subtract time-zone change from pre-travel CBTmin & add time-zone change to pre-travel CBTmin \\
\hline $\begin{array}{c}\text { Example: } \\
\text { if CBTmin home time is } 04: 00\end{array}$ & flying $8 \mathrm{~h}$ WEST $\boldsymbol{+}$ & flying $8 \mathrm{~h}$ EAST $\boldsymbol{H}$ \\
CBTmin will be at $20: 00$ destination time & CBTmin will be at 12 noon destination time \\
\hline
\end{tabular}

\section{Optimal timing of an intervention}

It is estimated that CBTmin naturally shifts by 0.5 days ( $2 \mathrm{~h}$ per day) per time-zone crossed WEST and 1 day (1h per day) per time-zone crossed EAST. Since this shift can be accelerated when applying an intervention, it is advised to shift the timing of interventions by $2 \mathrm{~h}$ per day when travelling WEST and $1 \mathrm{~h}$ per day when travelling EAST.

\section{Flight choice}

Important to aid with effective adaptation. If feasible, choose a flight with an arrival time to coincide with either the optimal period of light exposure or avoidance at the destination. (Fig 6)

\section{Short-term travel (1-3 days)}

Align sleep and meal times to destination time-zone, but do not try to shift the body clock.

Ensure adequate amount of sleep and employ strategic napping to reduce cumulative sleep debt.

Consider use of short-acting hypnotics if clinically indicated (e.g. Zolpidem 10mg; according to team medical protocols)

Maintain alertness with caffeine (dietary sources or anhydrous caffeine) at a dose of $1 \mathrm{mg} / \mathrm{kg}$ body mass (proven as effective with a lower risk of side-effects compared to higher doses)

Try to schedule all activities during the period of maximum alertness in the departure time-zone if feasible; this is dependent on the number of time-zones crossed

\section{Sleep disorders and altitude}

Refer Table 3 
after travel include adjusting the sleep-wake cycle to counter travel fatigue and maximising the rate at which the body clock adapts to the new time zone by specifying $3 \mathrm{~h}$ periods of light exposure and avoidance to reduce jet lag. Importantly, inappropriate exposure may be counter-productive causing detrimental side effects. Lastly, this review outlines specific steps to advance theory and practice in the field, suggesting detailed areas of future research on travel fatigue and jet lag management in athletes.

Recommended interventions to help prevent or reduce the effect of jet lag

\begin{tabular}{|c|c|c|}
\hline Non-pharmacological Interventions & $\begin{array}{l}\text { W WEST (Phase-delay) } \\
\text { CBTmin advance by } 0.5 \text { days ( } 2 \text { per day) per time-zone crossed during } \\
\text { adaptation [5] }\end{array}$ & $\begin{array}{l}\text { CBTmin delay by } 1 \text { day (1 } 1 \mathrm{~h} \text { per day) per time-zone crossed during } \\
\quad \text { adaptation [5] } \\
\text { [Consider delaying (moving backward) rather than advancing (moving } \\
\text { forward) especially for large time-zone changes }>8 \mathrm{~h} \text { ] }\end{array}$ \\
\hline \multicolumn{3}{|l|}{ Light [38-39] } \\
\hline $\begin{array}{l}\text { - Sunlight is the most dominant environmental signal for the circadian system } \\
\text { even on overcast days } \\
\text { - When required at sunrise or sunset, supplement with artificial bright light (light } \\
\text { boxes, bright indoor light, light-emitting sunglasses) } \\
\text { - Blue light spectrum filter glasses can limit light transmission by up to } 85 \% \\
\text { - Maximum delays or advances are subject to the duration of light exposure (0- } \\
\text { - In), shorter blue light } 400-495 \mathrm{~nm} \text {, at } \geq 2500 \text { lux intensity } \\
\text { - Inappropriate light exposure may interfere with sleep }\end{array}$ & 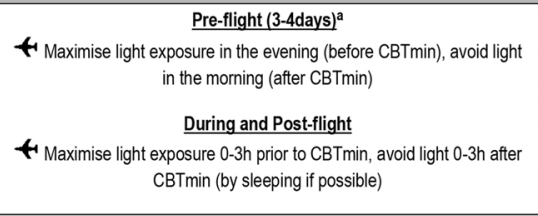 & $\begin{array}{c}\text { Pre-flight (3-4days) }^{\text {a }} \\
\begin{array}{c}\text { Avoid light in the evening (before CBTmin), maximise light exposure } \\
\text { in the morning (after CBTmin) }\end{array} \\
\text { During and Post-flight } \\
\text { Avoid light 0-3h prior to CBTmin (by sleeping if possible), maximise } \\
\text { light exposure 0-3h after CBTmin }\end{array}$ \\
\hline \multicolumn{3}{|l|}{ Sleep $^{b}[2,13,94,128-132]$} \\
\hline $\begin{array}{l}\text { - Optimal sleep: minimum of } 7-9 h \text { per day } \\
\text { - Sleep preservation is the mainstay of jet lag management as it counteracts the } \\
\text { effects of desynchronisation and sleep deprivation suffered from long flights } \\
\text { - A short interval between the last full sleep pre-travel and the first full sleep } \\
\text { post-travel may reduce jet lag } \\
\text { - When travelling west (phase delay), flight timing has to be strategic to allow for } \\
\text { players to sleep in to minimise sleep deprivation } \\
\text { - Attempt to arrange for housekeeping not to interfere with team sleep schedule } \\
\text { - Do not exercise or train in periods of recommended sleep time }\end{array}$ & \multicolumn{2}{|c|}{$\begin{array}{l}\text { - Attempt to sleep when possible, considering the "sleep window" aligned with night at the place of departure as the physiological drive for sleep will } \\
\text { be higher, and sleep initiation easier } \\
\text { - Consider the use of pharmacological aids, i.e. melatonin, sedatives. Inappropriate timing of melatonin ingestion can induce a phase shift in the wrong } \\
\text { direction } \\
\text { - Avoid caffeine and alcohol } \\
\text { - Wear comfortable, loose-fitting clothes } \\
\text { - Minimise use of electronic equipment } \\
\text { - Use sleep aids to cancel noise and movement, i.e. eye masks, neck pillows, earplugs } \\
\text { Post-flight } \\
\left.\text { - Apply good sleep hygiene practices at destination: i.e. ensure cool ( } 20^{\circ} \mathrm{C}\right) \text {, quiet and dark conditions when sleeping, dim room lights } 1 \mathrm{~h} \text { before } \\
\text { bedtime, minimise use of electronic equipment, avoid caffeine } \pm 6 h \text { before sleep } \\
13 \mathrm{~h} 00-16 \mathrm{ho0}\end{array}$} \\
\hline \multicolumn{3}{|l|}{ Exercise $[125,133]$} \\
\hline $\begin{array}{l}\text { - The appropriate time, intensity and duration of exercise may induce a phase } \\
\text { shift. However, limited evidence exists to provide accurate advice } \\
\text { - Effects of exercise coincide with the times for bright light exposure and } \\
\text { avoidance } \\
\text { - Coordination and agility are impaired following travel } \\
\text { - Low-intensity aerobic exercise assists in feeling less fatigued following travel }\end{array}$ & $\begin{array}{r}\text {-Switch from long-duration training to } \begin{array}{r}\text { Pre-flight } \\
\text { moderate } \\
\text { During }\end{array} \\
\text { - Periodic activity, every } \sim 2 \text { on outside of the "sleep window", e.g. } \\
\text { Post } \\
\text { - Vigorous exercise } \leq 1 \mathrm{~h} \text { before }\end{array}$ & $\begin{array}{l}\text { 3-4days) } \\
\text { raining intensity, of medium duration ( } 30-60 \mathrm{~min}) \\
\text { flight } \\
\text { sometric exercises, walks along the aisles or stretching exercises } \\
\text { light } \\
\text { 1). Limit exercise intensity and complexity of movement patterns in the first } \\
\text { d-eye coordination drills } \\
\text { edtime may interfere with sleep }\end{array}$ \\
\hline \multicolumn{3}{|l|}{ Nutrition $^{c}[20,82,134-137]$} \\
\hline $\begin{array}{l}\text { - Upfront planning and preparation to improve food choices and meet nutrition } \\
\text { needs (for optimal training, recovery, and performance) remain a key focus } \\
\text { (Table 3) } \\
\text { - Dietary intake can further amplify or reduce circadian adaptation and/or side- } \\
\text { effects of travel (e.g. fatigue, sleep disturbance, gastrointestinal (GI) } \\
\text { symptoms) } \\
\text { - Meal composition (carbohydrate, protein, fat) may potentially influence sleep } \\
\text { architecture; and eating pattern or routine of main meals (in tune with light- } \\
\text { dark cycle at destination) may enhance circadian adaptation }\end{array}$ & $\begin{array}{l}\text { - Gradually shift eating (and sleep) schedule by 30-60 min each } \\
\text { - Carbohydrate-rich meals eaten 1-4h pre-bedtime prom } \\
\text { - Avoid insufficient energy (calorie } \\
\text { - Avoid high fat intake (over 4-7 days), } \\
\text { - Follow the pattern of small, regular meals and/or snacks (bet } \\
\text { - Adjust to a pattern of eating regular meals tha } \\
\text { - Follow a pattern of small, regular meals or snacks (better } \\
\text { - Implement personal and foo }\end{array}$ & $\begin{array}{l}\text { 3-4days) } \\
\text { lay towards the destination time for a few days before departure. } \\
\text { te sleep (high-glycaemic index or easily digested meal) } \\
\text { intake, it may disturb sleep quality } \\
\text { it may negatively affect total sleep time } \\
\text { flight } \\
\text { er tolerated, improve Gl comfort) and general advice (Table 3) } \\
\text { light } \\
\text { align with the light-dark cycle at the destination } \\
\text { olerated, improve GI comfort) and general advice (Table 3) } \\
\text { hygiene standards (Table 3) }\end{array}$ \\
\hline \multicolumn{3}{|l|}{ Nutritionc (fluids) $[78,82,134]$} \\
\hline $\begin{array}{l}\text { - Increased loss of water from dry cabin air } \\
\text { - Poor hydration can amplify negative side-effects associated with travel } \\
\text { (headaches, constipation) }\end{array}$ & $\begin{array}{r}\begin{array}{r}\text { Pre- }{ }^{\mathrm{a}} \text {, During } \\
\text { - Follow current sports nutrition guidelines for maintaining optimal hydratio } \\
\text { pale yellow like lem }\end{array} \\
\text { - Habitual coffee or tea drinkers should not totally abstain, as it may rest } \\
\text { irrit } \\
\text { - Avoid alcohol altogether, and caffeine or caffeine-containing drinks } \pm 6 h \\
\text { resynch } \\
\text { - Do not consume fluids too late in the evening and/or large volu }\end{array}$ & $\begin{array}{l}\text { nd Post-flight } \\
\text { Urine colour can be used as a guide for hydration status (urine should be } \\
\text { n juice, low in odour) } \\
\text { It in reduced fluid intake and caffeine withdrawal symptoms (headaches, } \\
\text { bility) } \\
\text { oefore bed- or sleep time (interferes with quality of sleep and complicates } \\
\text { onisation) } \\
\text { mes just before bedtime as it may interrupt sleep due to nocturia }\end{array}$ \\
\hline
\end{tabular}

Fig. 4 Recommended interventions to help prevent or reduce the effect of jet lag 


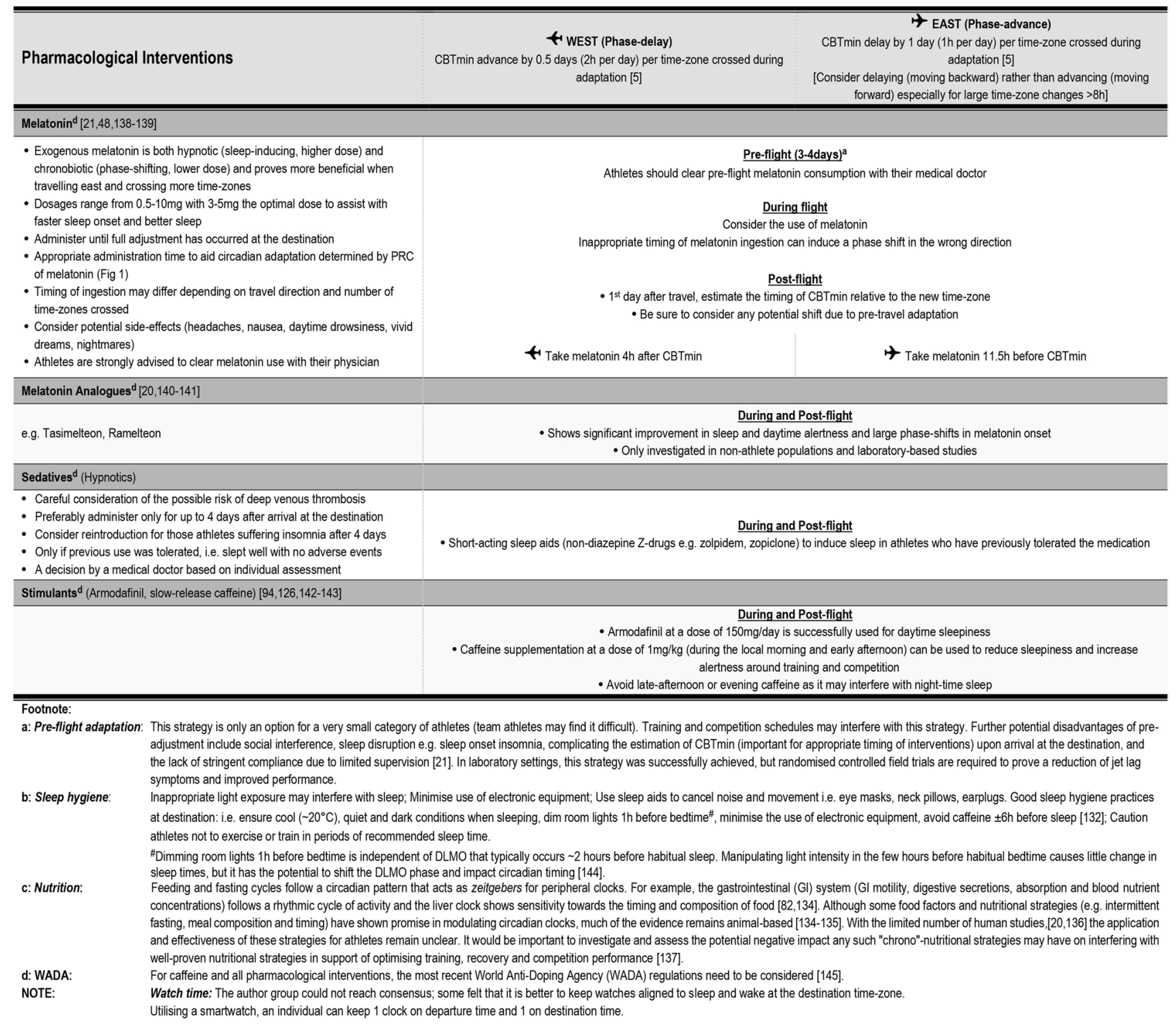

Fig. 4 (continued) 
Combined interventions and short-term travel recommendations to help prevent or reduce the effect of jet lag

f WEST (Phase-delay)

CBTmin advance by 0.5 days (2h per day) per time-zone crossed during adaptation [5]
$\$$ EAST (Phase-advance)

CBTmin delay by 1 day ( $1 \mathrm{~h}$ per day) per time-zone crossed during adaptation [5] [Consider delaying (moving backward) rather than advancing (moving forward) especially for large time-zone changes $>8 \mathrm{~h}]$

Combined interventions $\mathbf{s}^{\mathrm{a}, \mathrm{b}, \mathrm{c}, \mathrm{d}}[2,5,13,20-21,48,82,94,138]$

\section{Pre-flight (3-4days)}

- Education: discuss travel and expected effects. Make clear the policy on sleeping medication. Minimise anxiety around sleep disruption versus performance decrement - Athletes should clear pre-flight melatonin consumption with their medical doctor

+ Gradually move bedtime, wake-up time and nutrition schedule later (i.e. 30-60 min/day)

+ Maximise evening light exposure, minimise morning light exposure $\rightarrow$ Gradually move bedtime, wake-up time and nutrition schedule earlier (i.e. 30-60 min/day)

Minimise evening light exposure, maximise morning light exposure

During flight

- Attempt to sleep when possible, considering the "sleep window' aligned with night at the place of departure as the physiological drive for sleep will be higher, and sleep initiation easier - Plan appropriate food and fluid intake for athletes, including adaptations around travel delays - Melatonin during flight not recommended

+1 Maximise light exposure 0-3h before CBTmin, avoid light 0-3h after CBTmin (by sleeping if possible)

Haximise light exposure 0-3h after CBTmin, avoid 0-3h light prior to CBTmin (by sleeping if possible)

\section{Post-flight}

- Follow a sleep schedule that allows gradual re-alignment with the destination time-zone and assist with sleeping aids and sleeping tablets if needed, but based on an individualised basis. - Appropriate times to conduct exercise for its phase-shifting properties coincide with the appropriate times for light exposure

- Avoid eating heavy meals before bedtime, eat smaller meals more frequently to minimise gastrointestinal discomfort

- Structure the training day regarding alertness for complex tasks, shorten session time, use social interaction to maintain wakefulness at time of predictable sleepiness

+1 Maximise light exposure 0-3h before CBTmin, avoid light 0-3h after CBTmin (by sleeping if possible) + Take melatonin $4 \mathrm{~h}$ after CBTmin
H Maximise light exposure 0-3h after $\mathrm{CBTmin}$, avoid 0-3h light prior to $\mathrm{CBT}$ in (by sleeping if possible) $\rightarrow$ Take melatonin $11.5 \mathrm{~h}$ before CBTmin

Footnote:

Combined interventions: Consider the best net result e.g. referring to Figure 6 flying 4h WEST - proposed light exposure and sleep time coincides; depending on the immediate need of the athlete (fatigued or not) the decision will be to either opt for sleep or to rather get light exposure before bedtime.

a: Pre-flight adaptation: This strategy is only an option for a very small category of athletes (team athletes may find it difficult). Training and competition schedules may interfere with this strategy. Further potential disadvantages of pre-adjustment include social interference, sleep disruption e.g. sleep onset insomnia, complicating the estimation of CBTmin (important for appropriate timing of interventions) upon arrival at the destination, and the lack of stringent compliance due to limited supervision [21]. In laboratory settings, this strategy was successfully achieved, but randomised controlled field trials are required to prove a reduction of jet lag symptoms and improved performance.

b: Sleep hygiene: Inappropriate light exposure may interfere with sleep; Minimise use of electronic equipment; Use sleep aids to cancel noise and movement i.e. eye masks, neck pillows, earplugs. Good sleep hygiene practices at destination: i.e. ensure $\operatorname{cool}\left(\sim 20^{\circ} \mathrm{C}\right)$, quiet and dark conditions when sleeping, dim room lights $1 \mathrm{~h}$ before bedtime $\mathrm{e}^{\sharp}$, minimise the use of electronic equipment, avoid caffeine $\pm 6 \mathrm{~h}$ before sleep [132]; Caution athletes not to exercise or train in periods of recommended sleep time.

\#Dimming room lights $1 \mathrm{~h}$ before bedtime is independent of DLMO that typically occurs $~ 2$ hours before habitual sleep. Manipulating light intensity in the few hours before habitual bedtime causes little change in sleep times, but it has the potential to shift the DLMO phase and impact circadian timing [144]

c: Nutrition: $\quad$ Feeding and fasting cycles follow a circadian pattern that acts as zeitgebers for peripheral clocks. For example, the gastrointestinal (GI) system (GI motility, digestive secretions, absorption and blood nutrient concentrations) follows a rhythmic cycle of activity and the liver clock shows sensitivity towards the timing and composition of food [82,134]. Although some food factors and nutritional strategies (e.g. intermittent fasting, meal composition and timing) have shown promise in modulating circadian clocks, much of the evidence remains animal-based [134-135]. With the limited number of human studies the application and effectiveness of these strategies for athletes remain unclear $[20,136]$. It would be important to investigate and assess the potential negative impact any such "chrono"nutritional strategies may have on interfering with well-proven nutritional strategies in support of optimising training, recovery and competition performance [137].

d: WADA: $\quad$ For caffeine and all pharmacological interventions, the most recent World Anti-Doping Agency (WADA) regulations need to be considered [145].

NOTE: Watch time: The author group could not reach consensus; some felt that it is better to keep watches aligned to sleep and wake at the destination time-zone.

Utilising a smartwatch, an individual can keep 1 clock on departure time and 1 on destination time.

Fig. 5 Combined interventions and short-term travel recommendations to help prevent or reduce the effect of jet lag 
Fig. 6 The combined use of light (exposure or avoidance), exogenous melatonin ingestion and administration of shortacting hypnotics to facilitate adaptation to phase shifts from the day of arrival. a Depicts westward travel with the first row illustrating normal home time. The next three rows illustrate travel crossing 4,8 and $12 \mathrm{~h}$ time zones, respectively. Each row represents the current phase of the circadian system on the day of arrival. The CBTmin shifts by 0.5 days per time zone crossed, i.e. delays by $2 \mathrm{~h}$ per day and application of interventions need to be adapted according to the shifting of the CBTmin. b Depicts eastward travel with the first row illustrating normal home time. The next three rows illustrate travel crossing 4,8 and $12 \mathrm{~h}$ time zones, respectively. Each row represents the current phase of the circadian system on the day of arrival. The CBTmin shifts by 1 day per time zone crossed, i.e. advances by $1 \mathrm{~h}$ per day and application of interventions need to be adapted according to the shifting of the CBTmin. We constructed a recommendation based on a scientific measurement (CBTmin and DLMO) that can be reasonably applied for any number of time zones crossed. Travelling $>8 \mathrm{~h}$ EAST, it may be preferable to adapt by delay (moving backward) instead of advance (moving forward) as the body clock adjusts to large delays more easily than to large advances). Once CBTmin at the destination occurs within the scheduled sleep period, partial adaptation is achieved, and the individual is likely to encounter less sleep disruption. Once CBTmin at the destination occurs at the same time as pre-travel (home time), complete adaptation is achieved
Post-flight WEST - delay circadian rhythm (shift body clock backward)
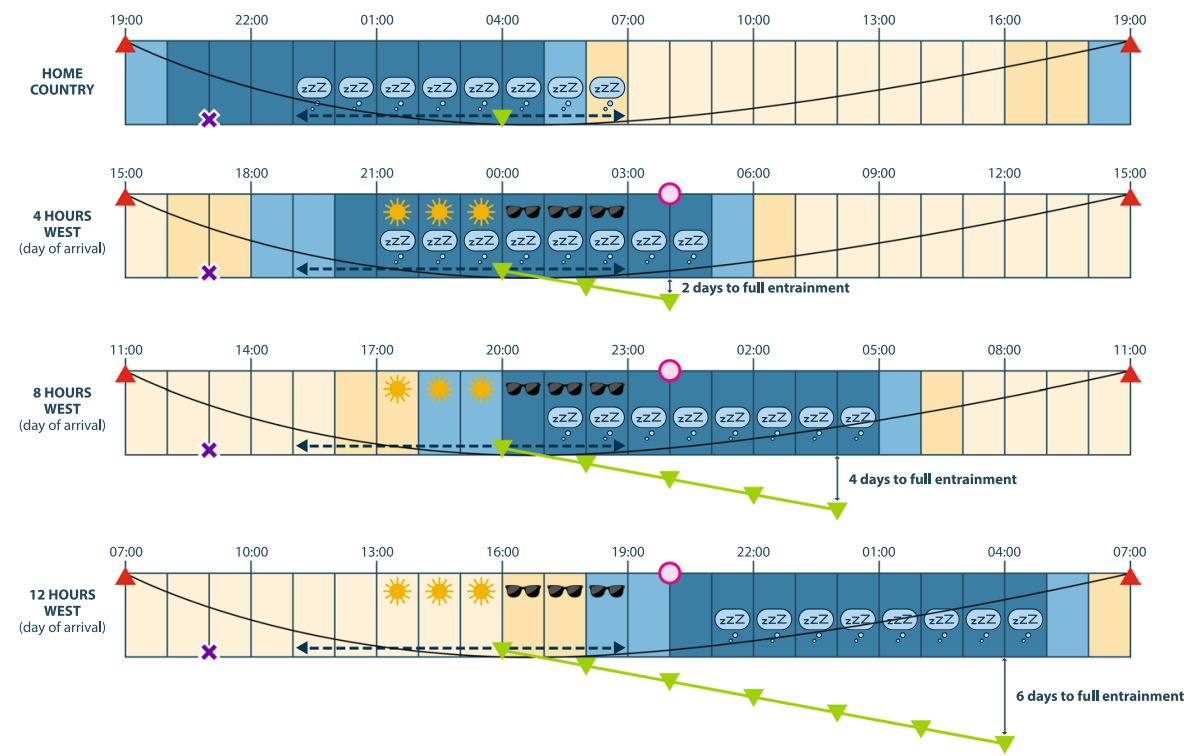

Post-flight EAST - advance circadian rhythm (shift body clock forward)
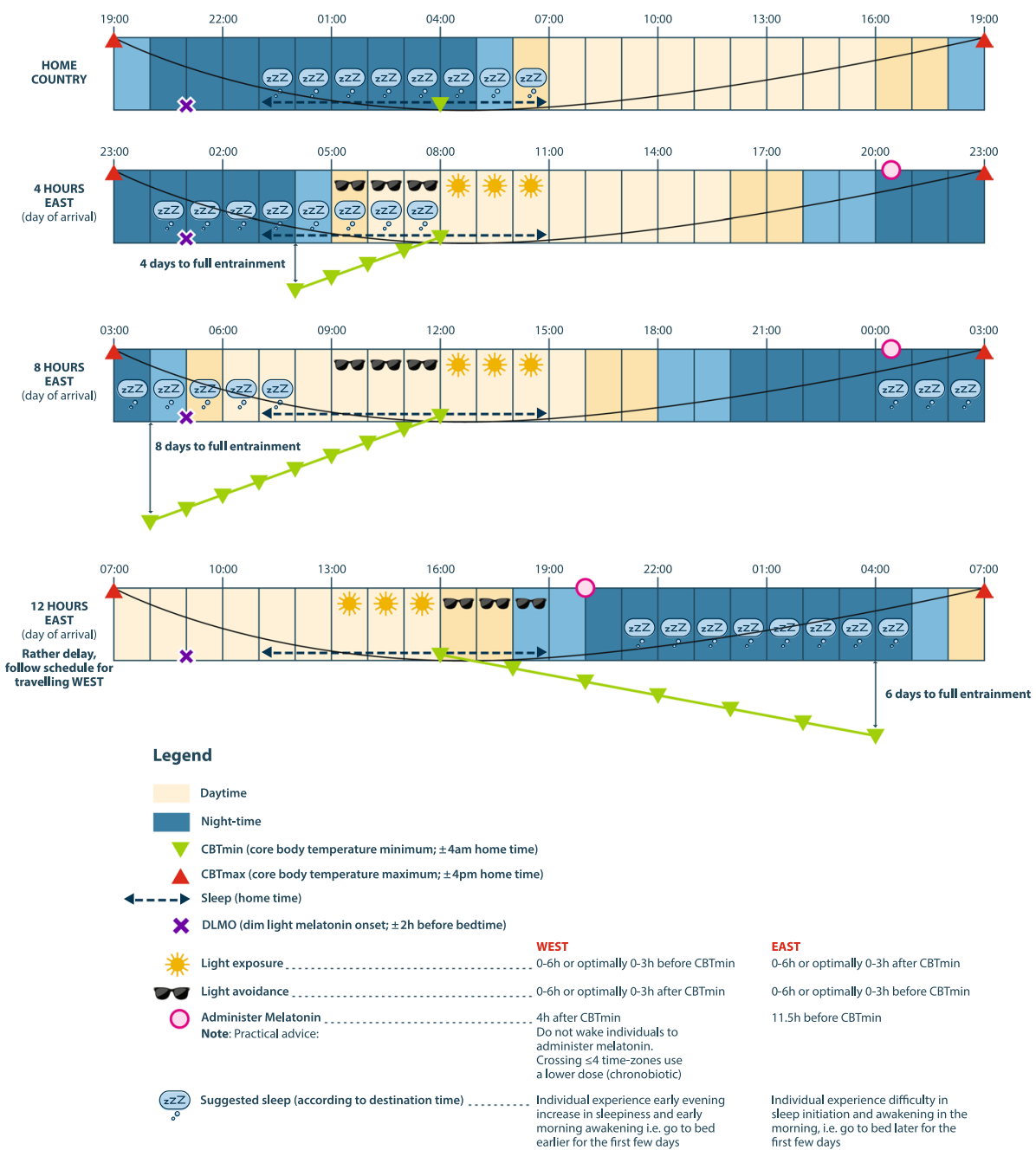

EAST

0-6h or optimally 0-3h after CBTmin

$0-6 \mathrm{~h}$ or optimally $0-3 \mathrm{~h}$ before $\mathrm{CBT}$ in 11.5h before CBTmin 
Supplementary Information The online version contains supplementary material available at https://doi.org/10.1007/s40279-021-01502-0.

Acknowledgements The authors would like to express their gratitude to Marizanne Booyens (Figs. 1 and 6) and to Heinrich Jansen van Rensburg (Figs. 2, 4 and 5) for the graphics, Mrs Brenda Weder for editing and Mrs Madeleen Scheepers for upload of publications to Endnote library.

\section{Declarations}

Funding No sources of funding were used to assist in the preparation of this article.

Conflict of interest Dina C (Christa) Janse Van Rensburg, Audrey Jansen van Rensburg, Peter M Fowler, Amy M Bender, David Stevens, Kieran O Sullivan, Hugh HK Fullagar, Juan-Manuel Alonso, Michelle Biggins, Amanda Claassen-Smithers, Rob Collins, Michiko Dohi, Matthew W Driller, Ian C Dunican, Luke Gupta, Shona L Halson, Michele Lastella, Kathleen H Miles, Mathieu Nedelec, Tony Page, Greg Roach, Charli Sargent, Meeta Singh, Grace E. Vincent, Jacopo A. Vitale, Tanita Botha declare that they have no conflicts of interest relevant to the content of this review.

Ethical approval Ethical approval was received from the University of Pretoria, South Africa (REC 428/2015).

Consent to participate Not applicable.

Consent for publication All Authors approved of this version for publication.

Availability of data and material Not applicable.

Code availability Not applicable.

Authors' contributions Dina C (Christa) Janse van Rensburg (DCJvR): consensus concept, manuscript planning, manuscript writing (first draft), development of surveys towards consensus voting, manuscript review and editing, approved the version to be published. Audrey Jansen van Rensburg (AJvR): manuscript planning, manuscript writing (first draft), development of surveys towards consensus voting, manuscript review and editing, approved the version to be published. Peter Fowler (PF): manuscript planning, manuscript writing (first draft), consensus voting, manuscript review and editing, approved the version to be published. Amy Bender (AB): group lead for terminology section, manuscript writing (first draft), development of surveys towards consensus voting, manuscript review and editing, approved the version to be published. David Stevens (DS): group lead for human circadian section, manuscript writing (first draft), consensus voting, manuscript review and editing, approved the version to be published. Kieran O Sullivan (KoS): group lead for travel fatigue section, manuscript writing (first draft), consensus voting, manuscript review and editing, approved the version to be published. Hugh Fullagar (HF): group lead for jet lag section, manuscript writing (first draft), consensus voting, manuscript review and editing, approved the version to be published. Tanita Botha (TB): statistician, manuscript writing (first draft), development of surveys towards consensus voting, analyses of surveys, manuscript review and editing, approved the version to be published. All other co-authors [Juan-Manuel Alonso (JMA), Michelle Biggins (MB), Amanda Claassen-Smithers (ACS), Rob Collins (RC), Michiko Dohi (MDo), Matthew Driller (MD), Ian Dunican (ID), Luke Gupta (LG), Shona Halson (SH), Michele Lastella (ML), Kathleen Miles (KM), Mathieu Nedelec (MN), Tony Page (TP), Greg Roach
(GR), Charli Sargent (CS), Meeta Singh (MS), Grace Vincent (GV), Jacopo A. Vitale (JV)] contributed to manuscript writing (first draft), consensus voting, manuscript review and editing, approved the final version to be published.

\section{References}

1. Arendt J, Marks V. Physiological changes underlying jet lag. Br Med J (Clin Res Ed). 1982;284(6310):144-6.

2. Waterhouse J, Reilly T, Atkinson G, Edwards B. Jet lag: trends and coping strategies. Lancet. 2007;369(9567):1117-29.

3. Van DCJR, van Rensburg AJ, Schwellnus MP. Coping with jet lag and protecting athlete health when travelling. Aspetar Sports Med J. 2019;8(19):214-22.

4. Samuels $\mathrm{CH}$. Jet lag and travel fatigue: a comprehensive management plan for sport medicine physicians and high-performance support teams. Clin J Sport Med. 2012;22(3):268-73.

5. Eastman CI, Burgess HJ. How to travel the world without jet lag. Sleep Med Clin. 2009;4(2):241-55.

6. McGuckin TA, Sinclair WH, Sealey RM, Bowman P. The effects of air travel on performance measures of elite Australian rugby league players. Eur J Sport Sci. 2014;14(sup1):S116-22.

7. Richmond LK, Dawson B, Stewart G, Cormack S, Hillman DR, Eastwood PR. The effect of interstate travel on the sleep patterns and performance of elite Australian Rules footballers. J Sci Med Sport. 2007;10(4):252-8.

8. Fowler P, Duffield R, Vaile J. Effects of domestic air travel on technical and tactical performance and recovery in soccer. Int $\mathrm{J}$ Sports Physiol Perform. 2014;9(3):378-86.

9. Fowler P, Duffield R, Vaile J. Effects of simulated domestic and international air travel on sleep, performance, and recovery for team sports. Scand J Med Sci Sports. 2015;25(3):441-51.

10. Reilly T, Waterhouse J, Edwards B. Some chronobiological and physiological problems associated with long-distance journeys. Travel Med Infect Dis. 2009;7(2):88-101.

11. Reilly T, Waterhouse J, Edwards B. Jet lag and air travel: implications for performance. Clin Sports Med. 2005;24(2):367-80.

12. Atkinson G, Batterham AM, Dowdall N, Thompson A, van Drongelen A. From animal cage to aircraft cabin: an overview of evidence translation in jet lag research. Eur J Appl Physiol. 2014;114(12):2459-68.

13. Arendt J. Managing jet lag: some of the problems and possible new solutions. Sleep Med Rev. 2009;13(4):249-56.

14. Reilly T, Atkinson G, Edwards B, Waterhouse J, Åkerstedt T, Davenne D, et al. Coping with jet-lag: a position statement for the European College of Sport Science. Eur J Sport Sci. 2007;7(1):1-7.

15. Foster RG, Kreitzman L. The rhythms of life: what your body clock means to you! Exp Physiol. 2014;99(4):599-606.

16. Zee PC, Attarian H, Videnovic A. Circadian rhythm abnormalities. Continuum. 2013;19(1 Sleep Disorders):132.

17. Golombek DA, Casiraghi LP, Agostino PV, Paladino N, Duhart JM, Plano SA, et al. The times they're a-changing: effects of circadian desynchronization on physiology and disease. J Physiol Paris. 2013;107(4):310-22.

18. Dibner C, Schibler U, Albrecht U. The mammalian circadian timing system: organization and coordination of central and peripheral clocks. Annu Rev Physiol. 2010;72:517-49.

19. Adan A, Archer SN, Hidalgo MP, Di Milia L, Natale V, Randler C. Circadian typology: a comprehensive review. Chronobiol Int. 2012;29(9):1153-75.

20. van Rensburg DCJ, van Rensburg AJ, Fowler P, Fullagar HK, Stevens D, Halson S, et al. How to manage travel fatigue and 
jet lag in athletes? A systematic review of interventions. Br J Sports Med. 2020;54(16):960-8. https://doi.org/10.1136/bjspo rts-2019-101635.

21. Roach GD, Sargent C. Interventions to minimise jet lag after westward and eastward flight. Front Physiol. 2019;10:927.

22. Harbour R, Miller J. A new system for grading recommendations in evidence based guidelines. BMJ. 2001;323(7308):334-6.

23. Diamond IR, Grant RC, Feldman BM, Pencharz PB, Ling SC, Moore AM, et al. Defining consensus: a systematic review recommends methodologic criteria for reporting of Delphi studies. J Clin Epidemiol. 2014;67(4):401-9.

24. Buchheit M. Houston, we still have a problem. Int J Sports Physiol Perform. 2017;12(8):1111-4.

25. Lewin R. Making waves: Irving Dardik and his superwave principle. Rodale; 2005.

26. Rollag MD, Berson DM, Provencio I. Melanopsin, ganglioncell photoreceptors, and mammalian photoentrainment. J Biol Rhythms. 2003;18(3):227-34.

27. Foster RG, Hankins MW. Circadian vision. Curr Biol. 2007;17(17):R746-51.

28. Foster RG. Neurobiology: bright blue times. Nature. 2005;433(7027):698.

29. Lucas RJ, Freedman MS, Muñoz M, Garcia-Fernández J-M, Foster RG. Regulation of the mammalian pineal by non-rod, noncone, ocular photoreceptors. Science. 1999;284(5413):505-7.

30. Simpson N, Gibbs E, Matheson G. Optimizing sleep to maximize performance: implications and recommendations for elite athletes. Scand J Med Sci Sports. 2017;27(3):266-74.

31. Hull JT, Czeisler CA, Lockley SW. Suppression of melatonin secretion in totally visually blind people by ocular exposure to white light: clinical characteristics. Ophthalmology. 2018;125(8):1160-71.

32. Borbély AA, Daan S, Wirz-Justice A, Deboer T. The twoprocess model of sleep regulation: a reappraisal. J Sleep Res. 2016;25(2):131-43.

33. Rupp TL, Wesensten NJ, Bliese PD, Balkin TJ. Banking sleep: realization of benefits during subsequent sleep restriction and recovery. Sleep. 2009;32(3):311-21.

34. Dement WC. Sleep extension: getting as much extra sleep as possible. Clin Sports Med. 2005;24(2):251-68.

35. Halberg F. The 24-hour scale: a time dimension of adaptive functional organization. Perspect Biol Med. 1960;3(4):491-527.

36. Patke A, Young MW, Axelrod S. Molecular mechanisms and physiological importance of circadian rhythms. Nat Rev Mol Cell Biol. 2020;21(2):67-84.

37. Martinez-Nicolas A, Madrid JA, Rol MA. Day-night contrast as source of health for the human circadian system. Chronobiol Int. 2014;31(3):382-93.

38. Roenneberg T, Merrow M. The circadian clock and human health. Curr Biol. 2016;26(10):R432-45.

39. Schulz P, Steimer T. Neurobiology of circadian systems. CNS Drugs. 2009;23(2):3-13.

40. Buttgereit F, Smolen JS, Coogan AN, Cajochen C. Clocking in chronobiology in rheumatoid arthritis. Nat Rev Rheumatol. 2015;11(6):349.

41. Hood S, Amir S. The aging clock: circadian rhythms and later life. J Clin Investig. 2017;127(2):437-46.

42. Baker FC, Waner JI, Vieira EF, Taylor SR, Driver HS, Mitchell D. Sleep and 24 hour body temperatures: a comparison in young men, naturally cycling women and women taking hormonal contraceptives. J Physiol. 2001;530(3):565-74.

43. Waterhouse J, Drust B, Weinert D, Edwards B, Gregson W, Atkinson G, et al. The circadian rhythm of core temperature: origin and some implications for exercise performance. Chronobiol Int. 2005;22(2):207-25.
44. Lack L, Lushington $\mathrm{K}$. The rhythms of human sleep propensity and core body temperature. J Sleep Res. 1996;5(1):1-11.

45. Krauchi K, Wirz-Justice A. Circadian rhythm of heat production, heart rate, and skin and core temperature under unmasking conditions in men. Am J Physiol Regul Integr Comp Physiol. 1994;267(3):R819-29.

46. Richardson GS. The human circadian system in normal and disordered sleep. J Clin Psychiatry. 2005;66(15):3-9.

47. Berry RB, Wagner MH. Sleep medicine pearls e-book. Elsevier; 2014.

48. Arendt J. Approaches to the pharmacological management of jet lag. Drugs. 2018;78(14):1419-31.

49. Bin YS, Postnova S, Cistulli PA. What works for jetlag? A systematic review of non-pharmacological interventions. Sleep Med Rev. 2019;43:47-59.

50. Barion A, Zee PC. A clinical approach to circadian rhythm sleep disorders. Sleep Med. 2007;8(6):566-77.

51. Kripke DF, Elliott JA, Youngstedt SD, Rex KM. Circadian phase response curves to light in older and young women and men. $\mathrm{J}$ Circadian Rhythms. 2007;5(1):1-13.

52. Zee PC. Science of circadian rhythms, an issue of sleep medicine clinics. Elsevier; 2015.

53. St Hilaire MA, Gooley JJ, Khalsa SBS, Kronauer RE, Czeisler CA, Lockley SW. Human phase response curve to a $1 \mathrm{~h}$ pulse of bright white light. J Physiol. 2012;590(13):3035-45.

54. Rüger M, St Hilaire MA, Brainard GC, Khalsa SBS, Kronauer RE, Czeisler CA, et al. Human phase response curve to a single $6.5 \mathrm{~h}$ pulse of short-wavelength light. J Physiol. 2013;591(1):353-63.

55. Atkinson G, Drust B, Reilly T, Waterhouse J. The relevance of melatonin to sports medicine and science. Sports Med. 2003;33(11):809-31.

56. LeGates TA, Fernandez DC, Hattar S. Light as a central modulator of circadian rhythms, sleep and affect. Nat Rev Neurosci. 2014;15(7):443-54.

57. Burgess HJ, Sharkey KM, Eastman CI. Bright light, dark and melatonin can promote circadian adaptation in night shift workers. Sleep Med Rev. 2002;6(5):407-20.

58. Vitale JA, Weydahl A. Chronotype, physical activity, and sport performance: a systematic review. Sports Med. 2017;47(9):1859-68.

59. Díaz-Morales JF. Morning and evening-types: exploring their personality styles. Pers Individ Differ. 2007;43(4):769-78.

60. Darwent D, Dawson D, Roach GD. Prediction of probabilistic sleep distributions following travel across multiple time zones. Sleep. 2010;33(2):185-95.

61. Reilly T, Atkinson G, Waterhouse J. Travel fatigue and jet-lag. J Sports Sci. 1997;15:365-9.

62. Postolache TT, Hung T-M, Rosenthal RN, Sorianoa JJ, Montese F, Stiller JW. Sports chronobiology consultation: from the lab to the arena. Clin Sports Med. 2005;24:415-56.

63. Wittmann M, Dinich J, Merrow M, Roenneberg T. Social jetlag: misalignment of biological and social time. Chronobiol Int. 2006;23(1-2):497-509.

64. Fabbian F, Zucchi B, De Giorgi A, Tiseo R, Boari B, Salmi R, et al. Chronotype, gender and general health. Chronobiol Int. 2016;33(7):863-82.

65. Montaruli A, Galasso L, Caumo A, Cè E, Pesenti C, Roveda E, et al. The circadian typology: the role of physical activity and melatonin. Sport Sci Health. 2017;13:469-476

66. Wennman H, Kronholm E, Partonen T, Peltonen M, Vasankari T, Borodulin K. Evening typology and morning tiredness associates with low leisure time physical activity and high sitting. Chronobiol Int. 2015;32(8):1090-100.

67. Vitale JA, La Torre A, Baldassarre R, Piacentini MF, Bonato M. Ratings of perceived exertion and self-reported mood state 
in response to high intensity interval training. A crossover study on the effect of chronotype. Front Psychol. 2017;8:1232.

68. Lastella M, Roach GD, Halson SL, Sargent C. The chronotype of elite athletes. J Hum Kinet. 2016;54(1):219-25.

69. Archer SN, Robilliard DL, Skene DJ, Smits M, Williams A, Arendt J, et al. A length polymorphism in the circadian clock gene Per3 is linked to delayed sleep phase syndrome and extreme diurnal preference. Sleep. 2003;26(4):413-5.

70. Reilly T. How can travelling athletes deal with jet-lag? Kinesiology. 2009;41(2):128-35.

71. Waterhouse J, Reilly T, Edwards B. The stress of travel. J Sports Sci. 2004;22(10):946-66.

72. Calleja-Gonzalez J, Marques-Jimenez D, Jones M, Huyghe T, Navarro F, Delextrat A, et al. What are we doing wrong when athletes report higher levels of fatigue from traveling than from training or competition? Front Psychol. 2020;11:194.

73. Flower DJ, Irvine D, Folkard S. Perception and predictability of travel fatigue after long-haul flights: a retrospective study. Aviat Space Environ Med. 2003;74(2):173-9.

74. Waterhouse J, Edwards B, Nevill A, Atkinson G, Reilly T, Davies $\mathrm{P}$, et al. Do subjective symptoms predict our perception of jetlag? Ergonomics. 2000;43(10):1514-27.

75. Cesarone MR, Belcaro G, Errichi BM, Nicolaides AN, Geroulakos G, Ippolito E, et al. The LONFLIT4-Concorde deep venous thrombosis and edema study: prevention with travel stockings. Angiology. 2003;54(2):143-54.

76. Basri B, Griffin MJ. Predicting discomfort from whole-body vertical vibration when sitting with an inclined backrest. Appl Ergon. 2013;44(3):423-34.

77. Smulders M, Naddeo A, Cappetti N, van Grondelle E, Schultheis U, Vink P. Neck posture and muscle activity in a reclined business class aircraft seat watching IFE with and without head support. Appl Ergon. 2019;79:25-37.

78. Hamada K, Doi T, Sakurai M, Matsumoto K, Yanagisawa K, Suzuki T, et al. Effects of hydration on fluid balance and lowerextremity blood viscosity during long airplane flights. JAMA. 2002;287(7):844-5.

79. Leatherwood WE, Dragoo JL. Effect of airline travel on performance: a review of the literature. Br J Sports Med. 2013;47(9):561-7.

80. Coste O, Van Beers P, Touitou Y. Hypoxia-induced changes in recovery sleep, core body temperature, urinary 6-sulphatoxymelatonin and free cortisol after a simulated long-duration flight. J Sleep Res. 2009;18(4):454-65.

81. Geertsema C, Williams AB, Dzendrowskyj P, Hanna C. Effect of commercial airline travel on oxygen saturation in athletes. $\mathrm{Br}$ J Sports Med. 2008;42(11):877-81.

82. Halson SL, Burke LM, Pearce J. Nutrition for travel: From jet lag to catering. Int J Sport Nutr Exerc Metab. 2019;29(2):228-35.

83. Lastella M, Roach GD, Sargent C. Travel fatigue and sleep/wake behaviors of professional soccer players during international competition. Sleep Health. 2019;5(2):141-7.

84. Thompson CJ, Noon M, Towlson C, Perry J, Coutts AJ, Harper $\mathrm{LD}$, et al. Understanding the presence of mental fatigue in English academy soccer players. J Sports Sci. 2020;38(13):1524-30.

85. Hede AJ. Using mindfulness to reduce the health effects of community reaction to aircraft noise. Noise Health. 2017;19(89):165.

86. Fowler P, Duffield R, Howle K, Waterson A, Vaile J. Effects of northbound long-haul international air travel on sleep quantity and subjective jet lag and wellness in professional Australian soccer players. Int J Sports Physiol Perform. 2015;10(5):648-54.

87. Sampaio J, McGarry T, Calleja-González J, Jiménez Sáiz S, del Alcázar XS, Balciunas M. Exploring game performance in the National Basketball Association using player tracking data. PLoS ONE. 2015;10(7):e0132894.
88. Macdonald B, Pulleyblank W. Realignment in the NHL, MLB, NFL, and NBA. J Quant Anal Sports. 2014;10(2):225-40.

89. Hooper SL, Mackinnon LT. Monitoring overtraining in athletes. Recommendations. Sports Med. 1995;20(5):321-7.

90. Kentta G, Hassmen P. Overtraining and recovery. A conceptual model. Sports Med. 1998;26(1):1-16 (PM:9739537).

91. Nässi A, Ferrauti A, Meyer T, Pfeiffer M, Kellmann M. Development of two short measures for recovery and stress in sport. Eur J Sport Sci. 2017;17(7):894-903.

92. Coutts AJ, Slattery KM, Wallace LK. Practical tests for monitoring performance, fatigue and recovery in triathletes. J Sci Med Sport. 2007;10(6):372-81.

93. van Rensburg DCJ, Fowler P, Racinais S. Practical tips to manage travel fatigue and jet lag in athletes. Br J Sports Med. 2020. https://doi.org/10.1136/bjsports-2020-103163.

94. Walsh NP, Halson SL, Sargent C, Roach GD, Nédélec M, Gupta L, et al. Sleep and the athlete: narrative review and 2021 expert consensus recommendations. Br J Sports Med. 2021;55(7):356-68.

95. Roach GD, Matthews R, Naweed A, Kontou TG, Sargent C. Flatout napping: the quantity and quality of sleep obtained in a seat during the daytime increase as the angle of recline of the seat increases. Chronobiol Int. 2018;35(6):872-83.

96. Berry RB, Gamaldo CE, Harding SM, Brooks R, Lloyd RM, Vaughn BV, Marcus CL. AASM Scoring Manual Version 2.2 updates: new chapters for scoring infant sleep staging and home sleep apnea testing. J Clin Sleep Med 2015;11(11):1253-4.

97. Dunican IC, Walsh J, Higgins CC, Jones MJ, Maddison K, Caldwell JA, et al. Prevalence of sleep disorders and sleep problems in an elite super rugby union team. J Sports Sci. 2019;37(8):950-7.

98. Saugy JJ, Schmitt L, Fallet S, Faiss R, Vesin J-M, Bertschi M, et al. Sleep disordered breathing during live high-train low in normobaric versus hypobaric hypoxia. High Alt Med Biol. 2016;17(3):233-8.

99. Sargent C, Schmidt WF, Aughey RJ, Bourdon PC, Soria R, Claros JCJ, et al. The impact of altitude on the sleep of young elite soccer players (ISA3600). Br J Sports Med. 2013;47(Suppl 1):i86-92.

100. Roach GD, Schmidt WF, Aughey RJ, Bourdon PC, Soria R, Claros JCJ, et al. The sleep of elite athletes at sea level and high altitude: a comparison of sea-level natives and high-altitude natives (ISA3600). Br J Sports Med. 2013;47(Suppl 1):i114-20.

101. Australian Institute of Sport AIS A message from the AIS CMO on travel risk management. Available from: https://www.sport aus.gov.au/media-centre/news/a-message-fromthe-ais-cmo-ontravel-risk-management. Accessed Aug 2020.

102. Baker LB, Jeukendrup AE. Optimal composition of fluid-replacement beverages. Compr Physiol. 2011;4(2):575-620.

103. Evans GH, James LJ, Shirreffs SM, Maughan RJ. Optimizing the restoration and maintenance of fluid balance after exerciseinduced dehydration. J Appl Physiol. 2017;122(4):945-51.

104. Wever RA. Phase shifts of human circadian rhythms due to shifts of artificial Zeitgebers. Chronobiologia. 1980;7:303-27.

105. Winget CM, DeRoshia CW, Markley CL, Holley DC. A review of human physiological and performance changes associated with desynchronosis of biological rhythms. Aviat Space Environ Med. 1984;55(12):1085-96.

106. Sack RL. Jet lag. N Engl J Med. 2010;362(5):440-7.

107. Ledger S, Bin YS, Nour M, Cistulli P, Bauman A, AllmanFarinelli $\mathrm{M}$, et al. Internal consistency and convergent and divergent validity of the Liverpool jetlag questionnaire. Chronobiol Int. 2020;37(2):218-26.

108. Spitzer R, Terman M, Williams J, Terman J, Malt U, Singer F, et al. Jet lag: clinical features, validation of a new syndromespecific scale, and lack of response to melatonin in a randomised, double-blind trial. Am J Psychiat. 1999;156:1392-6. 
109. Sack RL, Auckley D, Auger RR, Carskadon MA, Wright KP Jr, Vitiello MV, et al. Circadian rhythm sleep disorders: part I, basic principles, shift work and jet lag disorders. Sleep. 2007;30(11):1460-83.

110. Miller DJ, Sargent C, Vincent GE, Roach GD, Halson SL, Lastella M. Sleep/wake behaviours in elite athletes from three different football codes. J Sports Sci Med. 2017;16(4):604.

111. Fullagar HH, Duffield R, Skorski S, White D, Bloomfield J, Kölling S, et al. Sleep, travel, and recovery responses of national footballers during and after long-haul international air travel. Int J Sports Physiol Perform. 2016;11(1):86-95.

112. Paul MA, Miller JC, Gray GW, Love RJ, Lieberman HR, Arendt J. Melatonin treatment for eastward and westward travel preparation. Psychopharmacology. 2010;208(3):377-86.

113. Dijk DJ, Dufy J. Novel approaches for assessing circadian rhythmicity in humans: A review. J Biol Rhythms. 2020;35(5):421-38.

114. Dijk D-J, Duffy JF, Silva EJ, Shanahan TL, Boivin DB, Czeisler CA. Amplitude reduction and phase shifts of melatonin, cortisol and other circadian rhythms after a gradual advance of sleep and light exposure in humans. PLoS ONE. 2012;7(2):e30037.

115. Rutters F, Lemmens SG, Adam TC, Bremmer MA, Elders PJ, Nijpels G, et al. Is social jetlag associated with an adverse endocrine, behavioral, and cardiovascular risk profile? J Biol Rhythms. 2014;29(5):377-83.

116. British Airways. Jet lag advisor. Available from: https://www. britishairways.com/travel/drsleep/public/en_gb. Accessed 28 Jun 2020.

117. Jet Lag Rooster: In conjunction with the Mayo Clinic Center for Sleep Medicine and Rush University Medical Center. Available from: www.jetlagrooster.com. Accessed 28 Jun 2020.

118. Timeshifter. The Jet Lag App. Available from: https://www.times hifter.com/. Accessed 28 Jun 2020.

119. Simmons E, McGrane O, Wedmore I. Jet lag modification. Curr Sports Med Rep. 2015;14(2):123-8.

120. Fowler PM, Knez W, Crowcroft S, Mendham AE, Miller J, Sargent C, et al. Greater effect of east versus west travel on jet lag, sleep, and team sport performance. Med Sci Sports Exerc. 2017;49(12):2548-61.

121. Vitale KC, Owens R, Hopkins SR, Malhotra A. Sleep hygiene for optimizing recovery in athletes: review and recommendations. Int J Sports Med. 2019;40(8):535.

122. Leonardo-Mendonça RC, Martinez-Nicolas A, de Teresa GC, Ocaña-Wilhelmi J, Rusanova I, Guerra-Hernández E, et al. The benefits of four weeks of melatonin treatment on circadian patterns in resistance-trained athletes. Chronobiol Int. 2015;32(8):1125-34.

123. Jurvelin H, Takala T, Nissilä J, Timonen M, Rüger M, Jokelainen $\mathrm{J}$, et al. Transcranial bright light treatment via the ear canals in seasonal affective disorder: a randomized, double-blind doseresponse study. BMC Psychiatry. 2014;14(1):1-11.

124. Waterhouse J, Edwards B, Nevill A, Carvalho S, Atkinson G, Buckley P, et al. Identifying some determinants of "jet lag" and its symptoms: a study of athletes and other travellers. Br J Sports Med. 2002;36(1):54-60.

125. Youngstedt SD, Elliott JA, Kripke DF. Human circadian phaseresponse curves for exercise. J Physiol. 2019;597(8):2253-68.

126. Piérard C, Beaumont M, Enslen M, Chauffard F, Tan D-X, Reiter $\mathrm{RJ}$, et al. Resynchronization of hormonal rhythms after an eastbound flight in humans: effects of slow-release caffeine and melatonin. Eur J Appl Physiol. 2001;85(1-2):144-50.

127. Sainz I, Collado-Mateo D, Del Coso J. Effect of acute caffeine intake on hit accuracy and reaction time in professional e-sports players. Physiol Behav. 2020;224:113031.
128. Burke TM, Markwald RR, McHill AW, Chinoy ED, Snider JA, Bessman SC, et al. Effects of caffeine on the human circadian clock in vivo and in vitro. Sci Transl Med. 2015;7(305):305ra146.

129. Pujalte GG, Benjamin HJ. Sleep and the athlete. Curr Sports Med Rep. 2018;17(4):109-10.

130. Badr MS, Belenky G, Bliwise DL, Buxton OM, Buysse D, Dinges DF, et al. Recommended amount of sleep for a healthy adult: a joint consensus statement of the American Academy of Sleep Medicine and Sleep Research Society. J Clin Sleep Med. 2015;11(06):591-2.

131. Arnal PJ, Lapole T, Erblang M, Guillard M, Bourrilhon C, Leger D, et al. Sleep extension before sleep loss: effects on performance and neuromuscular function. Med Sci Sports Exerc. 2016;48(8):1595-603.

132. Drake C, Roehrs T, Shambroom J, Roth T. Caffeine effects on sleep taken 0, 3, or 6 hours before going to bed. J Clin Sleep Med. 2013;9(11):1195-200.

133. Stutz J, Eiholzer R, Spengler CM. Effects of evening exercise on sleep in healthy participants: a systematic review and metaanalysis. Sports Med. 2019;49(2):269-87.

134. Potter GD, Cade JE, Grant PJ, Hardie LJ. Nutrition and the circadian system. Br J Nutr. 2016;116(3):434-42.

135. Oike H. Modulation of circadian clocks by nutrients and food factors. Biosci Biotechnol Biochem. 2017;81(5):863-70.

136. Herxheimer A. Jet lag. BMJ Clin Evid. 2014;2014:2303.

137. Thomas D, Erdman K, Burke L, American College of Sports Medicine Joint Position Statement. Nutrition and athletic performance. Med Sci Sports Exerc. 2016;48(3):543-68.

138. Herxheimer A, Petrie KJ. Melatonin for the prevention and treatment of jet lag. Cochrane Database Syst Rev. 2002. Available from: https://www.cochranelibrary.com/cdsr/doi/10.1002/14651 858.CD001520/full. Accessed Jun 2018.

139. Morin CM, Benca R. Chronic insomnia. Lancet. 2012;379(9821):1129-41.

140. Rajaratnam SM, Polymeropoulos MH, Fisher DM, Roth T, Scott C, Birznieks G, et al. Melatonin agonist tasimelteon (VEC-162) for transient insomnia after sleep-time shift: two randomised controlled multicentre trials. Lancet. 2009;373(9662):482-91.

141. Zee PC, Wang-Weigand S, Wright KP Jr, Peng X, Roth T. Effects of ramelteon on insomnia symptoms induced by rapid, eastward travel. Sleep Med. 2010;11(6):525-33.

142. Cook CJ, Crewther BT, Kilduff LP, Drawer S, Gaviglio CM. Skill execution and sleep deprivation: effects of acute caffeine or creatine supplementation-a randomized placebo-controlled trial. J Int Soc Sports Nutr. 2011;8(1):2.

143. Beaumont M, Batejat D, Pierard C, Van Beers P, Denis J-B, Coste $\mathrm{O}$, et al. Caffeine or melatonin effects on sleep and sleepiness after rapid eastward transmeridian travel. J Appl Physiol. 2004;96(1):50-8.

144. Burgess HJ, Molina TA. Home lighting before usual bedtime impacts circadian timing: a field study. Photochem Photobiol. 2014;90(3):723-6.

145. WADA. World Anti-Doping Agency. Prohibited list. Montreal. Available from: https://www.wada-ama.org/en/what-we-do/prohi bited-list. Accessed Jun 2020.

146. Lo M, Aughey RJ, Stewart AM, Gill N, McDonald B. The road goes ever on and on-a socio-physiological analysis of travelrelated issues in Super Rugby. J Sports Sci. 2021;39(3):289-95.

147. Miles KH, Clark B, Fowler PM, Miller J, Pumpa KL. Sleep practices implemented by team sport coaches and sports science support staff: a potential avenue to improve athlete sleep? J Sci Med Sport. 2019;22(7):748-52. 


\section{Authors and Affiliations}

Dina C. Janse van Rensburg ${ }^{1,2}$ D $\cdot$ Audrey Jansen van Rensburg ${ }^{1}$ - Peter M. Fowler ${ }^{3}$ - Amy M. Bender ${ }^{4}$.

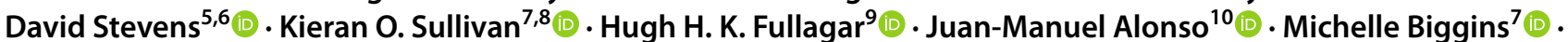
Amanda Claassen-Smithers ${ }^{11}$ (D) . Rob Collins ${ }^{12,13} \cdot$ Michiko Dohi $^{14} \cdot$ Matthew W. Driller $^{15}$ (D) Ian C. Dunican $^{16}$ (D) . Luke Gupta $^{17}$. Shona L. Halson ${ }^{18}$ (D) Michele Lastella ${ }^{19}$ (D) Kathleen H. Miles ${ }^{20}$ (D) Mathieu Nedelec M $^{21}$.

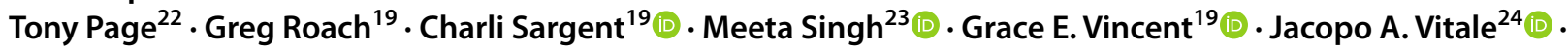
Tanita Botha 25 (i)

Audrey Jansen van Rensburg

audrey.jansenvanrensburg@up.ac.za

1 Section Sports Medicine and Sport Exercise Medicine and Lifestyle Institute (SEMLI), Faculty of Health Sciences, University of Pretoria, Sports Campus, South Street, Hatfield, Pretoria 0083, South Africa

2 International Netball Federation, Manchester, UK

3 School of Exercise and Nutrition Sciences, Queensland University of Technology, Brisbane, QLD, Australia

4 Faculty of Kinesiology, University of Calgary, Calgary, AB, Canada

5 Adelaide Institute for Sleep Health, College of Medicine and Public Health, Flinders University, Adelaide, South Australia, Australia

6 Centre for Nutrition and Gastrointestinal Diseases, South Australian Health and Medical Research Institute, Adelaide, South Australia, Australia

7 School of Allied Health, University of Limerick, Limerick, Ireland

8 Ageing Research Centre, University of Limerick, Limerick, Ireland

$9 \quad$ School of Sport, Exercise and Rehabilitation, Faculty of Health, University of Technology Sydney, Sydney, NSW, Australia

10 Sports Medicine Department, Aspetar Hospital, Doha, Qatar

11 Education and Research Department, South African Institute for Drug-Free Sport, Cape Town, South Africa

12 Medical Department, Golden Lions Rugby Union, Johannesburg, South Africa
13 Section Sports Medicine, Faculty of Health Sciences, University of Pretoria, Pretoria, South Africa

14 Sport Medical Center, Japan Institute of Sports Sciences, Tokyo, Japan

15 Sport and Exercise, School of Allied Health, Human Services and Sport, La Trobe University, Melbourne, Australia

16 Centre for Sleep Science, School of Human Sciences, University of Western Australia, Perth, Australia

17 English Institute of Sport, Bisham Abbey National High Performance Centre, Marlow, UK

18 School of Behavioural and Health Sciences, Australian Catholic University, Brisbane, QLD, Australia

19 Appleton Institute for Behavioural Science, Central Queensland University, Adelaide, QLD, Australia

20 Research Institute for Sport and Exercise, University of Canberra, Canberra, Australia

21 Laboratory of Sport, Expertise and Performance (EA 7370), French National Institute of Sport (INSEP), Paris, France

22 Team Doctor All Blacks Rugby Team, Christchurch, New Zealand

23 Henry Ford Sleep Disorders Center, Detroit, MI, USA

24 Laboratory of Movement and Sport Science, IRCCS Istituto Ortopedico Galeazzi, Milan, Italy

25 Department of Statistics, Faculty of Natural and Agricultural Sciences, University of Pretoria, Pretoria, South Africa 